\title{
The development of building assessment criteria framework for sustainable non- residential buildings in Saudi Arabia
}

Article

Accepted Version

Creative Commons: Attribution-Noncommercial-No Derivative Works 4.0

Banani, R., Vahdati, M. M., Shahrestani, M. and ClementsCroome, D. (2016) The development of building assessment criteria framework for sustainable non-residential buildings in Saudi Arabia. Sustainable Cities and Society, 26. pp. 289-305. ISSN 2210-6707 doi: https://doi.org/10.1016/j.scs.2016.07.007 Available at https://centaur.reading.ac.uk/66256/

It is advisable to refer to the publisher's version if you intend to cite from the work. See Guidance on citing.

To link to this article DOI: http://dx.doi.org/10.1016/j.scs.2016.07.007

Publisher: Elsevier

All outputs in CentAUR are protected by Intellectual Property Rights law, including copyright law. Copyright and IPR is retained by the creators or other copyright holders. Terms and conditions for use of this material are defined in the End User Agreement.

www.reading.ac.uk/centaur 
Central Archive at the University of Reading

Reading's research outputs online 
The development of building assessment criteria framework for sustainable non-residential buildings in Saudi Arabia

Authors:

Raji Bannani ${ }^{\text {a }}$, Maria M Vahdati ${ }^{a} *$, Mehdi Shahrestani ${ }^{\mathrm{a}}$, Derek Clements-Croome ${ }^{\mathrm{a}}$

${ }^{\text {a }}$ School of the Built Environment, University of Reading, RG6 6AY, UK

*Corresponding author: Dr Maria M Vahdati, University of Reading, School of the Built Environment, Whiteknights Campus, Reading, RG6 6AY, UK

$\underline{\text { m.m.vahdati@ reading.ac.uk }}$

Highlights:

- The development of building assessment criteria framework for Saudi Arabia

- The consideration of social factors in advancing sustainable construction in Saudi Arabia

- The environmental factors are the most important aspect of sustainability in Saudi Arabia

- There is a strong relationship between local context and buildings sustainability assessments 


\begin{abstract}
To quantify the environmental impacts of building construction, many environmental assessment methods for measuring building performance have been proposed worldwide, such as BREEAM (UK), LEED (US) and Green Star (AU). However, much debate exists about the efficacy of these international assessment tools in measuring building performance outside their country of origin, due to global variations in climate, geography, economics and culture. To address this debate, this study proposes a framework for developing domestic sustainable non-residential building assessment criteria for Saudi Arabia. To create this framework, five major building assessment methods were compared with respect to their application methods, major characteristics and categories. Surveys were conducted with a range of Saudi sustainable construction experts to gain their expertise in reflecting the local context of Saudi Arabian construction. The analytical Hierarchy Process (AHP) method was applied to evaluate survey data. Nine criteria and 36 sub-criteria were defined in this study for inclusion as the most appropriate assessment criteria for sustainable non-residential construction in Saudi Arabia. These criteria include water efficiency and energy efficiency, indoor air quality, materials selection, effective management, land and waste, whole-life cost, quality of service and cultural aspects.
\end{abstract}

Keywords: Saudi Arabia, Building environmental Assessment method, Sustainability, Sustainable Construction, Building Performance, BRREAM, LEED, Culture. 


\section{List of abbreviations}

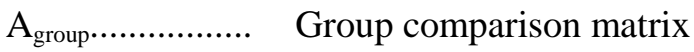

AHP Analytical Hierarchy Process

BREEAM. Building Research Establishment's Environmental Assessment Method

CASBEE Comprehensive Assessment System for Building Environmental Efficiency

CI. The Consistency Index

CR. The Consistency Ratio

HVAC Heating, ventilating and air-conditioning system

IEQ. Indoor Environment Quality

KACARE. ... King Abdullah City for Atomic and Renewable Energy

KAFD King Abdullah Financial District

LEED. Leadership in Energy and Environmental Design

QSAS Qatar Sustainability Assessment System

RI. Random Consistency Index

SAT. Saudi Assessment Criteria of sustainable buildings for non-residential purposes

SBC Saudi Building Code

SGBC Saudi Green Building Council

SuBET Sustainable Built Environment Tool

UAE The United Arab Emirates

USGBC U.S. Green Building Council's

W. Vector of weights (eigenvector)

$\lambda_{\max }$ Principle eigenvalue 


\section{Introduction}

The Kingdom of Saudi Arabia is a major oil exporting country and produced $15.7 \%$ of the global oil supply in 2014 (BP, 2014). Rapid population growth in Saudi Arabia has expanded its construction industry, resulting in increased demand for new buildings, and in turn greater resource consumption (Lahn and Stevens, 2011). As a result, in 2010 the Saudi government launched the Saudi Green Building Council (SGBC) to apply the concept of green buildings into construction projects (SGBC, 2011).

Recent construction projects such as the King Abdullah City for Atomic and Renewable Energy (KACARE), was planned using the Sustainable Built Environment Tool (SuBET) framework to achieve a high sustainable urban design standard (Alwaer and ClementsCroome, 2010). Another example is the King Abdullah Financial District (KAFD) project, which adopted an applied sustainability design approach to deliver a number of key objectives, such as minimising water use and energy consumptions, improving indoor air quality, and reducing greenhouse gas emissions (Kurek, 2007). However, while the industry has used tools specific to sustainable construction, to date no assessment tools has been developed that broadly considers Saudi Arabia's specific climatic, societal and cultural contexts. Hence, there is a need to develop a building sustainability assessment tool to measure the extent to which the sustainability agenda are implemented in buildings in Saudi Arabia.

Previous studies have highlight that assessment methods created for one nation or region might not be applicable to others (Cole, 1999; Darus et al., 2009; Reed et al., 2009). In addition, a number of environmental factors may prevent the transfer of currently available environmental assessment tools to other nations (Mao et al., 2009; Alyami and Rezgui, 2012; Suzer, 2015). Some of these factors include; climate, geography, resource consumption, understanding of building stocks, the vernacular architecture, government policies and regulation, historical context, cultural values and level of public awareness. Many, if not all, of these factors vary across global regions. Therefore an understanding of the concept of sustainability for a given region may change with respect to these factors. Indeed, even designing environmental assessment tools applicable to a single nation where climate and topography vary could be a challenge. For example, Ali and Al Nsairat (2009) concluded that Jordan should develop a range of domestic environmental assessment methods due to its variations in climate and topography. 
Saudi Arabia exhibits a range of different climates, cultures and topographic features and would benefit from implementing a domestic assessment method of measuring building performance.

In the last decade BREEAM and LEED attempted to make their assessment tools compatible with conditions of different regions in the World including the Middle East. However, it is revealed that they were not able to fully incorporate the social and cultural elements in the satiability assessment criteria. For instance, although BREEAM has released a BREEAM Gulf/Middle East assessment system, it was strongly influenced by BREEAM-UK, which assessed buildings based on the UK (Alyami and Rezgui, 2012). In another study, Todd et al. (2001) highlighted the importance of considering economic, social and cultural factors for developing domestic rating methods in developing countries. Importance of considering these elements in environmental and sustainable assessment tools has been also addressed in many studies in this field ( Forsberg and Von Malmborg (2004); Sinou and Kyvelou (2006); Haapio and Viitaniemi (2008a); Mao et al. (2009))

A number of Arabian countries in the Middle East have introduced domestic building assessment tools. For example, the United Arab Emirates (UAE) has introduced Estidama (AUPC, 2010b) and the Qatar Sustainability Assessment System (QSAS) is used in Qatar (GORD, 2012). Therefore, it would be beneficial for Saudi Arabia to develop its own assessment method, which ideally should consider a number of factors, such as vernacular architecture as well as cultural, social and economic contexts (Alyami and Rezgui, 2012).

Recently, the SGBC adopted the U.S. Green Building Council's (USGBC) LEED criteria as its official assessment tool for measuring building performance in Saudi Arabia (SGBC, 2011). However, there are presently no specific assessment tools that encompass the economic, social and cultural aspects in the assessment criteria.

To date, in terms of applying green building concepts and tools in Saudi Arabia, most attention has been paid to residential buildings (Taleb et al., 2011; Alyami et al., 2013; Attia, 2013). However, new government policies encouraging international investment to improve private and national industry development have spurred commercial construction in the Saudi construction industry (Ameen et al., 2015). As a result, these is an increasing demand for non-residential buildings nationwide. To ensure success in implementation of the concept of sustainability in the building sector, architects, contractors, environmental engineers, clients and allied professionals should have a better Saudi-specific 
understanding of, and information about, the relationship between the various aspects of sustainability in non-residential construction projects.

\section{Criteria of the buildings environmental assessment tools}

Most building environmental assessment tools are similar in some of their criteria, which typically focus on site protection, energy and water consumptions, indoor environment quality, building materials, waste, pollution, resources, transportation and innovation (Forsberg and Von Malmborg, 2004; Dirlich, 2011; Kajikawa et al., 2011). These criteria are regarded as facets of the interaction between buildings and their environment (Reijnders and van Roekel, 1999). However, Dixon et al. (2007) believe that this common agreement between different assessment schemes indicates negligence of the economic and social aspects of sustainability, which could lead to a loss of balance among sustainability dimensions, thereby missing the real goals of sustainable development (Goh and Rowlinson, 2013). Furthermore, these tools were developed for a certain geographic context largely without considering regional variations in environment, economics and culture (Cole, 1998; Ding, 2008; Alyami and Rezgui, 2012). Hence, adapting an assessment tool requires significant adjustment of its criteria, priorities, weighting coefficients and scoring benchmarks (Darus et al., 2009; Kajikawa et al., 2011; Attia, 2013).

Haapio and Viitaniemi (2008a) reviewed the predominant building environmental assessment tools developed in Europe and North America. To analyse these assessment methods, the authors categorised sixteen existing building environmental assessment tools using two classification methods: ATHENA and IEA Annex 31 (Energy Related Environmental Impact of Buildings). Based on these methods, the studied tools were classified into two principal categories so called, interactive software and passive tools. The study reported that a consideration of the experiences of different tool users- - such as architects, engineers, and contractors - is important in developing assessment tools that tend to be defined differently due to varying cultures and regions. Haapio and Viitaniemi (2008a) concluded that in addition to environmental factors, existing building assessment tools should incorporate economic and cultural aspects to effectively transform into sustainability assessment tools. 
Moreover, inflexibility, complexity and lack of consideration of weighting systems are identified as major barriers to the acceptance of any particular assessment method (Ding, 2008).

\subsection{Weighting Methods for Assessment Criteria}

Almost all building assessment schemes, including BREEAM and LEED, share some common criteria such as water and energy consumptions for assessing building performance (Lee et al., 2002). However, the severity of these factors can vary across regions, depending on local factors such as climate, materials and building stock (Ding, 2008; Rahardjati et al., 2010; Kajikawa et al., 2011). Ding (2008) has suggested that a weighting system can provide opportunities to enhance environmental assessment scales through accommodating these regional variations.

Abdalla et al. (2011) examined the approach of LEED with respect to weighting environmental parameters to determine regional priorities. They analysed the regional priority credits assigned for several LEED case studies in four different countries: Canada, Turkey, China and Egypt. The outcomes of research highlighted the weighting system as the core asset for an environmental assessment method. In addition, it is concluded that the lack of such a weighting system that allows for adjustments with respect to local priorities could be considered a fundamental drawback of the LEED system. This has been also implied in other research that developing a weighting system is a necessary phase in prioritising each assessment criterion to accommodate a particular local context (Ali and Al Nsairat, 2009; Alyami and Rezgui, 2012; Shaawat and Jamil, 2014). For example, the highest possible assessment ranking is 'excellent' for BREEAM and 'platinum' for LEED. However, after comparing both systems, researchers found that LEED's 'platnium' rank is approximately equal to BREEAM's second-highest rating, 'very good', rather than to its 'excellent' rating. This difference is due to the variation in building codes and regulations between countries (Reed et al., 2011). This suggests that the weighting system of respective sustainable criteria may be described as the identity of each assessment scheme by reflecting the needs of the region for which it is developed.

According to Lee et al. (2002), weighting systems could be regarded as the heart of building assessment schemes, as they govern the overall performance score of the building. Nevertheless, no consensus-based approach or satisfactory method exists. The 
objective weighting method often overlooks decision-makers' concerns and experts' experiences, which is considered as a disadvantage (Yang et al., 2010). Furthermore, Wang et al. (2009) concluded that subjective weighting is superior to objective weighting in clarifying evaluations.

Rosa and Haddad (2013) discussed the implementation of sustainability concepts for buildings in Brazil. This study analysed a number of building assessment tools-such as LEED, IPT, BREEAM, CASBEE and GBTool-to establish a set of variables to assess sustainability for school buildings. Key social, economic and environmental factors for Rio de Janeiro were identified through field visits and informal interviews with sustainability experts. The authors used the AHP method to determine the relative importance of variables, which included criteria, sub-criteria and groups of indicators. Moreover, the consistency of the data was examined, and inconsistent data was returned to the surveyed experts for additional review. Results showed that the AHP method could provide solutions for complex problems involving multiple criteria, stakeholders and decision makers in scenarios of high uncertainty and high risk. Also, this method presents a compromise between targets, understanding and objectivity through its use of simple calculations, which allowed lay people to rank tangible and intangible factors as a process of conflict resolution or in order of priority.

Considering the need for a sustainable building assessment tool, this study has developed a set of assessment criteria considering the unique attributes of economy, culture and social life in Saudi Arabia. In this study the most influential elements associated with the concept of sustainability in non-domestic buildings are identified and the Analytical Hierarchy Process (AHP) has been adopted to assess the weight of the criteria for Saudi Arabia.

\section{Research design}

The study was designed to first develop assessment criteria for sustainable buildings in Saudi Arabia through qualitative research methods. The resultant criteria were then used to develop priorities and weights through quantitative research methods (Figure 1). Research data was drawn from three main sources: literature, semi-structured interviews and survey questionnaires.

The research was divided into four main stages: establishing, refining and weighting the assessment criteria, as shown in Figure 1. To establish initial criteria for assessing 
sustainable building projects, a combination of existing assessment tools, academic research, and Saudi government and industry reports were reviewed in the first stage of this research.

The main objective of the second research stage was to refine the list of assessment criteria derived in the first stage (Figure 1). This second stage discussed the local context of Saudi Arabia and considered climate, topography, natural resources and the development of the Saudi construction industry. To understand the practical issues for operationalising these core concepts, a scoping study was carried out and unstructured interviews were conducted with a number of construction professionals. Then, semi-structured interviews were conducted as the main data collection method to consolidate the findings from the literature and, based on content analysis, exclude criteria irrelevant for the Saudi Arabian context. The results of this content analysis were used to investigate appropriate assessment criteria for Saudi Arabian assessment tools.

As shown in Figure 1, weighting and prioritising criteria were the aims of the third stage of the research design. The questionnaire technique was used by reconfiguring the refined criteria results from the second research stage into a set of pairwise comparisons in order to determine the relative weights of the derived criteria. Then, these subjective weights of the criteria were evaluated using the Analytical Hierarchy Process (AHP) method.

The fourth and final stage in this study was to formulate a rating criteria framework for assessing sustainable non-residential buildings based on the findings of research stages two and three. Finally, this research proposes a framework for developing assessment criteria for sustainable non-residential building in Saudi Arabia.

In this study, a comprehensive set of criteria for the proposed environmental assessment tool has been identified through the review of the existing assessment schemes available in the open literature together with survey and semi-structured interviews with 18 academics and experts including designers, project managers and policy makers in the field. Academics contributed in the criteria identification process by addressing the latest academic achievements and concerns over the very broad area of sustainability, and experts by highlighting the deficiencies of the existing assessment tools. Through this process, it is believed that the identified criteria are capable of representing the main concerns and needs raised by academic and experts in construction industry. 
The interviewees were carefully selected considering the following criteria:

- No fewer than two years of experience in the sustainable construction field and the use of assessment tools in the Saudi construction industry;

- Employment as a university academic/construction consultant or membership in a construction organisation;

- In possession of a formal professional title, such as architect, engineer or associate professor.

Snowball sampling, a non-probability sampling technique, was selected to identify the qualified participants for this research (Saunders et al., 2009). Initially, 37 participants were selected for interviews. However, in some cases, either participant unavailability or the inability to arrange interviews led to a decreased interview pool of 22 final participants. The results of the interviews were coded and analysed using NVivo10 software and the responses to the questionnaires were carefully analysed using the consistency analysis (Saaty, 2010). The outcomes of this analysis revealed that among 22 questionnaires four responses were not consistent and therefore they were excluded from the study. 


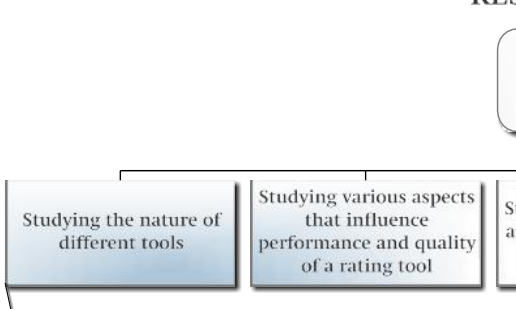

LITERATURE REVIEW

$\mid$\begin{tabular}{c|c|c|}
$\begin{array}{c}\text { Studying the nature of } \\
\text { different tools }\end{array}$ & $\begin{array}{c}\text { Studying various aspects } \\
\text { that influence } \\
\text { performance and quality } \\
\text { of a rating tool }\end{array}$ \\
\hline
\end{tabular}

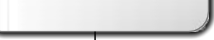

(1)

Studying the similarities $\mid$ Studving the relationship $\mid$ Studying the role of

and differences between

various tools

between tool elements

stem criteria within a

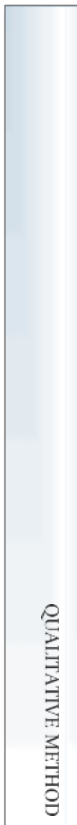

OLS COMPARATIVE REVIEW

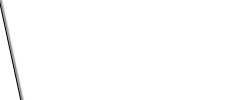

Finding strengths and weaknesses

I

nding the relationship between tools

Finding the different between systems criteria

Finding the gaps within system criteria

DERIVATIVE SUSTAINABLE ASSESSMENT CRITERIA
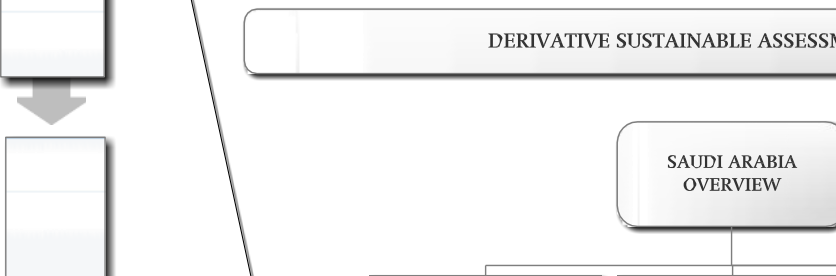

\begin{tabular}{|l|l} 
Identify Saudi Arabia \\
context
\end{tabular}

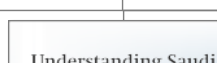
Understanding
needs

Understanding the and building
and

SCOOPING (NON-STRUCTURED INTERVIEWS)
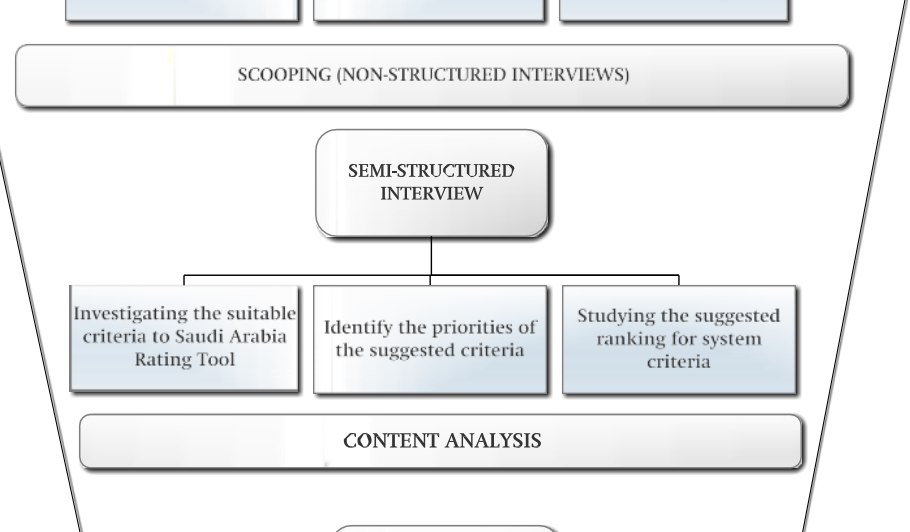

FORMULATE RATING FRAMEWORK BASED ON FINDINGS OF STAGE 2 AND 3

CONCLUSION, LIMITATION, AND RECOMMENDATION FOR FURTHER WORK

Figure 1 Research design framework for developing sustainable non-residential building assessment criteria for Saudi Arabia 


\section{Comparing the assessment criteria used in the exiting schemes}

BREEAM measures Building Energy Performance (BEP) along with $\mathrm{CO}_{2}$ emission reductions with the target of net zero emissions. On the other hand, LEED emphasises reduction of energy costs for $\mathrm{BEP}$, rather than $\mathrm{CO}_{2}$ emissions, which is in line with the standards of American Society of Heating, Refrigerating and Air-conditioning Engineers (ASHRAE). Green Star follows the BREEAM method for measuring BEP by modeling emissions reductions in relation to National Australian Built Environment Rating System (NABERS) Energy methodology. Estidama assesses BEP with different standards, including either those of the American National Standards Institute (ANSI), ASHRAE and the Illuminating Engineering Society of North America (IESNA) or local codes, whichever are more stringent. However, CASBEE takes a different approach to assessing BEP, focusing on the percentage of improvement for annual energy use relative to a Performance Rating Method (PRM) based on performance standard (PAL values:21.9) with applied efficiency in building service systems and efficient operation to the energy category. The five assessment methods evaluate most major water quantity and quality parameters. Waste criteria and their parameters are integral to all of the five assessment methods. Within the broad waste criterion, waste management and recycling emerge as the most prominent parameters, due to their importance in minimizing the negative impacts of waste generation for humans and the surrounding environment (Terry et al., 2008). Construction materials is another important element of environmental assessment methods due to the impact of material consumption on building users and the environment (Franzoni, 2011; Alyami and Rezgui, 2012). The Green Guide to Specification lists more than 1500 specifications used for various building types to assist designers and engineers in evaluating materials with respect to performance, environmental impact and responsible sourcing (BRE, 2015). On the other hand, LEED emphasises the location of materials in a building with little consideration given to responsible sourcing. Following LEED, the CASBEE and Estidama schemes encourage the use of locally manufactured materials, but are not as stringent as BREEAM in addressing material criteria. In terms of cost considerations, Estidama and Green star both assess materials while calculating their cost in relation to project construction.

High indoor environmental quality (IEQ) is considered a key objective for all building assessment methods (Alyami and Rezgui, 2012). BREEAM includes this category under 
its Health and Wellbeing section and along with ventilation and HVAC systems. At the same time, LEED assesses this category through low-emitting materials criteria but largely omits parameters addressing sound insulation and absorption, simply assessing noise level (Kawazu et al., 2005a; Alyami and Rezgui, 2012). Green Star assesses IEQ through air conditioning systems and lighting, and CASBEE covers the category under the Indoor Quality (Q1) sub-category of its Built Environment Quality category (Q). Estidama assesses IEQ under its Livable Indoors category, and gives more consideration to material emissions and thermal comfort. Finally, BREEAM and Estidama are the only tools that consider safe and secure environments as a parameter of their respective indoor quality environment categories.

All five assessment schemes include emission and pollution categories. BREEAM, Green Star and CASBEE are the only tools that include dedicated categories for these issues; LEED and Estidama address emissions and pollution across their respective frameworks. BREEAM covers the issue under a pollution category that evaluates refrigerant issues alongside pollution and emissions, such as $\mathrm{CO}_{2}$ and NOx. Similarly, the Green Star tool addresses these topics much the same as BREEAM, but under an emissions category. Finally, CASBEE assesses with emissions and pollutions under a local environment criterion.

Land use categories focus on site selection, site reuse and site protection criteria, with the aim of reducing soil erosion and groundwater contamination while improving site conditions. Land use and ecology is a prominent category that comprises $10 \%$ of the weighting system for both the BREEAM and Green Star tools and $8 \%$ for the Green Star system.

LEED addresses land use and ecology with its Sustainable Sites category with 26 possible points. The CASBEE system uses its Outdoor environment on-site category to consider of land use and ecology, and for Estidama, it is considered under the Natural system and Livable Outdoors categories with a weight of 12 and 37 credit points, respectively. BREEAM considers ecological protection as its primary parameter, while for LEED site selection is highly important. Green Star focuses more on the ecological value of the project site, while CASBEE focuses on a site's local characteristics, urban fabric and landscape. Estidama addresses natural resource management, sustainable land use and creation and habitat restoration (Kawazu et al., 2005a). On the other hand, BREEAM, LEED and Green Star deemphasize urban fabric, landscape, local characteristics and 
outdoor amenity criteria, all of which are given considerably more importance in the CASBEE and Estidama frameworks.

BREEAM and Green Star consider management in a discrete category, while LEED, CASBEE and Estidama distribute management parameters across several assessment categories.

Along with managing construction impacts on site, the management metric aims to address the entire project life cycle. It aims to ensure appropriate project commissioning and provides building operation and maintenance guidelines for building users. Commissioning and environmental management are management sub-categories common to all five schemes. Green star focuses on commissioning and environmental management, CASBEE prioritises maintenance planning and management, and Estidama and LEED explicitly address the management of indoor air quality and materials. However, compared to LEED, Estidama includes more management categories, such as the inclusion of project user guidelines and protecting sites during construction activities.

BREEAM covers sustainable management principles more comprehensively than LEED and CASBEE (Alyami and Rezgui, 2012). In addition, BREEAM is the only tool of the five that highlights the importance of stakeholder participation, in which all relevant parties are identified and consulted by the design team before key design decisions are made (BRE, 2011).

BREEAM considers cost efficiency under its Management category, while for Estidama it is grouped under Integrated Development Process. Building element costs (i.e. energy and materials) is the most widely used criterion considered in the majority of the assessment methods (BREEAM, LEED, Green star and Estidama). Operation and maintenance costs are included in the BREEAM, LEED, and Estidama tools but not in Green Star and CASBEE. .

Nearly all of the tools evaluated in this study offer innovation credits to encourage and support sustainability measures not specifically addressed by their respective assessment methods (USGBC, 2009; BRE, 2011). Innovation in project design, strategies, technologies, practices, performance and cultural issues are addressed in these categories. BREEAM and LEED both afford similar innovation criteria, and tend to encourage performance innovation through design, strategy and technology. Green Star offers 
innovation criteria to foster environmental benefits and the industry's transition to sustainable building practices (GBCA, 2012). To date, CASBEE does not consider innovation criteria in its evaluation framework. Of all these tools, Estidama features a unique method of covering innovation category criteria through rewarding design that reflects the cultural identity of the region (AUPC, 2010a). Furthermore, Estidama awards credits for innovative practices intended to encourage responsive design to enhance regional sustainable development, providing cost reductions and feasibility analyses for design that showcases cultural and regional practices.

All five schemes include transportation criteria in their assessment frameworks. However, only BREEAM and Green Star consider transportation as individual category in their respective frameworks; LEED, CASBEE and Estidama distribute transportation assessments across the scoring process. BREEAM groups mobility and transportation under its Transport category, with the exception of its Travel Plan category, which relates to public transport accessibility (Sleeuw, 2011b). LEED evaluates transportation under its Sustainable Sites category, focusing greater attention on public transportation access and bicycle facilities. Green Star accounts for mobility and transportation under its Transport category, focusing on car parking provision and cycling facilities but excluding community facilities. CASBEE considered mobility and transportation under Off-site environment category with taking more care for community facilities and bicycle facilities. Although, Estidama has no individual category for mobility and transportation, hence it covers same criteria under Livable Buildings category likewise BREEAM.

Five widely used commercial tools have been compared for the purposes of this study and the features that characterise each of these prominent assessment tools is shown in Table 1. 
Table 1 Environmental Rating Tools Features (USGBC, 2009b; AUPC, 2010a; BRE, 2011; IBEC, 2011; GBCA, 2012)

\begin{tabular}{|c|c|c|c|c|c|}
\hline & BREEAM & LEED & Green star & CASBEE & Estidama \\
\hline Developer/Year & $\begin{array}{l}\text { U. K. Building Research } \\
\text { Establishment (BRE); } 1990\end{array}$ & $\begin{array}{l}\text { U. S. Green Buildings Council } \\
\text { (USGBC); } 1998\end{array}$ & $\begin{array}{l}\text { Green Building Council } \\
\text { Australia (GBCA); } 2002\end{array}$ & $\begin{array}{l}\text { Japan Sustainable Building } \\
\text { Consortium (JSBC); } 2001\end{array}$ & $\begin{array}{l}\text { Abu Dhabi Urban Planning } \\
\text { Council (UPC); } 2008\end{array}$ \\
\hline Building phases & $\begin{array}{l}\text { Design, Construction and } \\
\text { Operation }\end{array}$ & $\begin{array}{l}\text { Design, Construction and } \\
\text { Operation }\end{array}$ & $\begin{array}{l}\text { Design, Construction and } \\
\text { Operation }\end{array}$ & $\begin{array}{l}\text { Design, Construction, Operation } \\
\text { and Deconstruction }\end{array}$ & $\begin{array}{l}\text { Design, Construction and } \\
\text { Operation (under development) }\end{array}$ \\
\hline Building types & $\begin{array}{l}\text {-Office } \\
\text {-Housing } \\
\text {-Healthcare } \\
\text {-Courts } \\
\text {-Industrial Units } \\
\text {-Retail } \\
\text {-Schools } \\
\text {-Multi-residential } \\
\text {-Schools } \\
\text {-Neighbourhoods }\end{array}$ & $\begin{array}{l}\text {-Offices } \\
\text {-Homes } \\
\text {-Neighbourhoods Development } \\
\text {-Retail } \\
\text {-Healthcare } \\
\text {-Schools }\end{array}$ & $\begin{array}{l}\text {-Education } \\
\text {-Healthcare } \\
\text {-Industrial } \\
\text {-Multi-residential } \\
\text {-Office } \\
\text {-Office Interiors } \\
\text {-Retail Centre }\end{array}$ & $\begin{array}{l}\text {-Residential } \\
\text {-Office } \\
\text {-Schools } \\
\text {-Retail } \\
\text {-Health care } \\
\text {-Urban development } \\
\text {-Cities }\end{array}$ & $\begin{array}{l}\text {-Offices } \\
\text {-Retail } \\
\text {-Multi-residential } \\
\text {-Schools }\end{array}$ \\
\hline Scope & $\begin{array}{l}\text {-New construction } \\
\text {-Refurbishment } \\
\text {-Existing buildings }\end{array}$ & $\begin{array}{l}\text {-New construction } \\
\text {-Refurbishment } \\
\text {-Existing buildings }\end{array}$ & $\begin{array}{l}\text {-New construction } \\
\text {-Refurbishment } \\
\text {-Existing buildings }\end{array}$ & $\begin{array}{l}\text {-New construction } \\
\text {-Refurbishment } \\
\text {-Existing buildings }\end{array}$ & $\begin{array}{l}\text {-New construction } \\
\text {-Existing buildings }\end{array}$ \\
\hline Categories & $\begin{array}{l}\text {-Management } \\
\text {-Health \& Wellbeing } \\
\text {-Energy } \\
\text {-Transport } \\
\text {-Water } \\
\text {-Materials } \\
\text {-Land Use and Ecology } \\
\text {-Waste } \\
\text {-Pollution } \\
\text {-Innovation (additional) }\end{array}$ & $\begin{array}{l}\text {-Sustainable Sites } \\
\text {-Water Efficiency } \\
\text {-Energy and Atmosphere } \\
\text {-Materials and Resources } \\
\text {-Indoor Environmental quality } \\
\text {-Innovation and Design Process } \\
\text {-Regional Priority credits }\end{array}$ & $\begin{array}{l}\text {-Management } \\
\text {-Indoor environmental quality } \\
\text {-Energy } \\
\text {-Transport } \\
\text {-Water } \\
\text {-Materials } \\
\text {-Land Use and Ecology } \\
\text {-Emissions } \\
\text {-Innovation }\end{array}$ & $\begin{array}{l}\text { Environmental Quality }(\mathbf{Q}) \\
\text {-Indoor Environment } \\
\text {-Quality of Service } \\
\text {-Outdoor Environment on Site } \\
\text { Environmental Load (L) } \\
\text {-Energy } \\
\text {-Resources and Materials } \\
\text {-Off-site Environment } \\
\text { BEE (Building Environmental } \\
\text { Efficiency)= Q/L }\end{array}$ & $\begin{array}{l}\text {-Integrated Development Process } \\
\text {-Natural Systems } \\
\text {-Livable Buildings } \\
\text {-Precious Water } \\
\text {-Resourceful Energy } \\
\text {-Stewarding Materials } \\
\text {-Innovating Practice }\end{array}$ \\
\hline Rating & $\begin{array}{l}\text {-Pass } \\
\text {-Good } \\
\text {-Very Good } \\
\text {-Excellent } \\
\text {-Outstanding }\end{array}$ & $\begin{array}{l}\text {-Certified } \\
\text {-Silver } \\
\text {-Gold } \\
\text {-Platinum }\end{array}$ & $\begin{array}{l}-1-3 \text { Stars } \\
-4 \text { Stars } \\
-5 \text { Stars } \\
-6 \text { Stars }\end{array}$ & $\begin{array}{l}\text {-Poor (C) } \\
\text {-Slightly Poor (B-) } \\
\text {-Good (B+) } \\
\text {-Very Good (A) } \\
\text {-Superior (S) }\end{array}$ & $\begin{array}{l}-1 \text { Pearl } \\
-2 \text { Pearl } \\
-3 \text { Pearl } \\
-4 \text { Pearl } \\
-5 \text { Pearl }\end{array}$ \\
\hline Update interval & Annual & As required & Annual & As required & Not available \\
\hline $\begin{array}{l}\text { Number of certified } \\
\text { projects }\end{array}$ & 425,000 & 65.044 & 78 & 11,000 & Not available \\
\hline International use & $\begin{array}{l}\text { Canada, Hong Kong, Netherlands } \\
\text { and others }\end{array}$ & $\begin{array}{l}\text { United Arab Emirates, India, } \\
\text { Brazil and others }\end{array}$ & New Zealand and South Africa & - & - \\
\hline
\end{tabular}


While assessment tool categories are broadly comparable, differences in their parameters do not allow for direct comparison (Sleeuw, 2011a). A comparison of BREEAM, LEED, Green Star, CASBEE and Estidama assessment tools is made in this section based on the dimensions of sustainability: environmental, economic, social and cultural. This study defines energy, water, waste, materials, indoor environmental quality, emissions and pollution, land use, site and ecology and management as the primary environmental assessment factors (Table 2).

Table 2 Comparison of rating tools criteria

\begin{tabular}{|c|c|c|c|c|c|}
\hline Category & BREEAM & LEED & $\begin{array}{c}\text { Green } \\
\text { Star }\end{array}$ & CASBEE & Estidama \\
\hline Energy & $\checkmark$ & $\checkmark$ & $\checkmark$ & $\checkmark$ & $\checkmark$ \\
\hline Water & $\checkmark$ & $\checkmark$ & $\checkmark$ & $\checkmark$ & $\checkmark$ \\
\hline Waste & $\checkmark$ & $\checkmark$ & $\checkmark$ & $\checkmark$ & $\checkmark$ \\
\hline Materials & $\checkmark$ & $\checkmark$ & $\checkmark$ & $\checkmark$ & $\checkmark$ \\
\hline Indoor Environment Quality & $\checkmark$ & $\checkmark$ & $\checkmark$ & $\checkmark$ & $\checkmark$ \\
\hline Economics & $\mathrm{x}$ & $x$ & $\mathrm{x}$ & $\mathrm{x}$ & $\checkmark$ \\
\hline Management & $\checkmark$ & $x$ & $\checkmark$ & $\checkmark$ & $\checkmark$ \\
\hline Mobility and Transportation & $\checkmark$ & $\checkmark$ & $\checkmark$ & $x$ & $\checkmark$ \\
\hline Emission and Pollution & $\checkmark$ & $\checkmark$ & $\checkmark$ & $\checkmark$ & $\checkmark$ \\
\hline Land Use, Site and Ecology & $\checkmark$ & $\checkmark$ & $\checkmark$ & $\mathrm{x}$ & $\checkmark$ \\
\hline Resources & $\mathrm{x}$ & $\checkmark$ & $\mathrm{x}$ & $\checkmark$ & $\mathrm{x}$ \\
\hline Cultural and Social & $x$ & $x$ & $x$ & $x$ & $\checkmark$ \\
\hline
\end{tabular}

Energy is considered a key category for all assessment methods due to its high environmental impact and necessity for the construction sector. Comparison of rating approach for energy performance assessment is provided in Table 3.

Table 3 the comparison of rating approach for energy performance assessment

\begin{tabular}{|c|c|c|c|c|c|}
\hline & BREEAM & LEED & Green Star & CASBEE & Estidama \\
\hline $\begin{array}{l}\text { Assessment } \\
\text { Method }\end{array}$ & $\begin{array}{l}\text { UK National } \\
\text { Calculation } \\
\text { Methodology (NCM) } \\
\text { based on Approved } \\
\text { Document Part L. }\end{array}$ & $\begin{array}{l}\text { Performance rating } \\
\text { method (PRM) based } \\
\text { on ASHRAE 90.1- } \\
2004 \text { Appendix G }\end{array}$ & $\begin{array}{l}\text { National } \\
\text { Australian Built } \\
\text { Environmental } \\
\text { Rating System } \\
\text { (NABERS) } \\
\text { Energy } \\
\text { methodology }\end{array}$ & $\begin{array}{l}\text { Performance } \\
\text { rating method } \\
\text { (PRM) based on } \\
\text { PAL values. }\end{array}$ & $\begin{array}{l}\text { Performance rating } \\
\text { method (PRM) based } \\
\text { on ANSI/ ASHRAE/ } \\
\text { IESNA Standard 90.1- } \\
2007 \text { Appendix G or } \\
\text { local code, whichever } \\
\text { is more stringent }\end{array}$ \\
\hline $\begin{array}{l}\text { Scope of } \\
\text { assessment }\end{array}$ & $\begin{array}{l}\text { Energy performance } \\
\text { certificate (EPC) } \\
\text { rating: } \mathrm{CO} 2 \text { based } \\
\text { index }\end{array}$ & $\begin{array}{l}\text { Improvement } \\
\text { percentage based on } \\
\text { annual energy cost }\end{array}$ & $\begin{array}{l}\text { Predicted GHG } \\
\text { emission }\end{array}$ & $\begin{array}{l}\text { Improvement } \\
\text { percentage based } \\
\text { on annual energy } \\
\text { use }\end{array}$ & $\begin{array}{l}\text { Improvement } \\
\text { percentage based on } \\
\text { annual energy } \\
\text { consumption }\end{array}$ \\
\hline $\begin{array}{l}\text { Simulation } \\
\text { tool }\end{array}$ & $\begin{array}{l}\text { Approved software } \\
\text { interfaces to SBEM } \\
\text { method. Approved } \\
\text { Dynamic Simulation } \\
\text { Modelling software }\end{array}$ & $\begin{array}{l}\text { Software approved } \\
\text { by the rating } \\
\text { authority and subject } \\
\text { to requirements in } \\
\text { ASHRAE 90.1-2004 } \\
\text { Appendix G }\end{array}$ & $\begin{array}{l}\text { Software must } \\
\text { meet the } \\
\text { requirements laid } \\
\text { down in Green } \\
\text { Star Office Design } \\
\text { Tool }\end{array}$ & $\begin{array}{l}\text { HASP/ACSS and } \\
\text { BECS and BEST } \\
\text { or able to } \\
\text { simulate the } \\
\text { hour-by-hour } \\
\text { energy }\end{array}$ & $\begin{array}{l}\text { Software approved by } \\
\text { the rating authority } \\
\text { and subject to } \\
\text { requirements specified } \\
\text { in Appendix G of } \\
\text { ASHRAE } 90.1-2007\end{array}$ \\
\hline
\end{tabular}


The main factors used in the studied assessment tools are contrasted and provided in Table 4,

Table 4 Comparison of the main elements associated with the principal elements associated with the assessment tools

\begin{tabular}{|c|c|c|c|c|c|c|}
\hline & Subcategories & 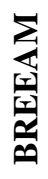 & 团 & 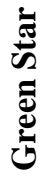 & 䆓 & 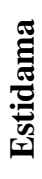 \\
\hline \multirow{8}{*}{ 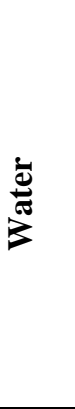 } & Potable water Consumption & $\checkmark$ & $\checkmark$ & $\checkmark$ & $\checkmark$ & $\checkmark$ \\
\hline & Monitoring & $\checkmark$ & $\mathrm{x}$ & $\checkmark$ & $\mathrm{x}$ & $\checkmark$ \\
\hline & Leak Detection & $\checkmark$ & $\mathrm{x}$ & $\mathrm{x}$ & $\mathrm{x}$ & $\checkmark$ \\
\hline & Water Quality and alternative Sources & $\checkmark$ & $\checkmark$ & $\checkmark$ & $\checkmark$ & $\checkmark$ \\
\hline & Irrigation use & $\checkmark$ & $\checkmark$ & $\checkmark$ & $\mathrm{x}$ & $\checkmark$ \\
\hline & Grey water & $\checkmark$ & $\checkmark$ & $\checkmark$ & $\checkmark$ & $\checkmark$ \\
\hline & Heat Rejection & $x$ & $\mathrm{x}$ & $\checkmark$ & $\checkmark$ & $\checkmark$ \\
\hline & Reduction Landscaping & $\checkmark$ & $\checkmark$ & $\mathrm{x}$ & $\mathrm{x}$ & $\checkmark$ \\
\hline \multirow{3}{*}{\begin{tabular}{l}
$\frac{0}{\tilde{W}}$ \\
\multirow{\pi}{*}{}
\end{tabular}} & Construction waste management & $\checkmark$ & $\checkmark$ & $\checkmark$ & $\checkmark$ & $\checkmark$ \\
\hline & Operational waste & $\checkmark$ & $\mathrm{x}$ & $\mathrm{x}$ & $\checkmark$ & $\checkmark$ \\
\hline & Waste strategies and recycling & $\checkmark$ & $\checkmark$ & $\checkmark$ & $\checkmark$ & $\checkmark$ \\
\hline \multirow{7}{*}{ 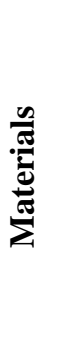 } & Low impact on life cycle & $\checkmark$ & $\checkmark$ & $\checkmark$ & $\checkmark$ & $\checkmark$ \\
\hline & Responsible Sourcing & $\checkmark$ & $\mathrm{x}$ & $\mathrm{x}$ & $\mathrm{x}$ & $\mathrm{x}$ \\
\hline & Used of Re-use Materials and Disassembly Design & $\checkmark$ & $\checkmark$ & $\checkmark$ & $\checkmark$ & $\checkmark$ \\
\hline & Renewable Materials & $\checkmark$ & $\checkmark$ & $\mathrm{x}$ & $\checkmark$ & $\checkmark$ \\
\hline & Insulation & $\checkmark$ & $\checkmark$ & $\mathrm{x}$ & $\checkmark$ & $\checkmark$ \\
\hline & Region Materials & $\mathrm{x}$ & $\checkmark$ & $\mathrm{x}$ & $\checkmark$ & $\checkmark$ \\
\hline & Materials Cost & $\mathrm{x}$ & $\mathrm{x}$ & $\checkmark$ & $\mathrm{x}$ & $\checkmark$ \\
\hline \multirow{11}{*}{$\underset{0}{O}$} & Link with surrounding area- View out & $\checkmark$ & $\checkmark$ & $\checkmark$ & $\checkmark$ & $\checkmark$ \\
\hline & Average daylight factor & $\checkmark$ & $\checkmark$ & $\mathrm{x}$ & $\checkmark$ & $\mathrm{x}$ \\
\hline & The amount of light (illuminance) and glare control & $\checkmark$ & $\checkmark$ & $\checkmark$ & $\checkmark$ & $\checkmark$ \\
\hline & Noise level & $\checkmark$ & $\checkmark$ & $\checkmark$ & $\checkmark$ & $\checkmark$ \\
\hline & Sound insulation and absorption & $\checkmark$ & $\mathrm{x}$ & $\mathrm{x}$ & $\checkmark$ & $\mathrm{x}$ \\
\hline & Ventilation and fresh air system and rate & $\checkmark$ & $\checkmark$ & $\checkmark$ & $\checkmark$ & $\checkmark$ \\
\hline & Ventilation sensors & $\checkmark$ & $\checkmark$ & $\checkmark$ & $\checkmark$ & $\checkmark$ \\
\hline & Smoke Control & $\mathrm{x}$ & $\checkmark$ & $\mathrm{x}$ & $\checkmark$ & $\checkmark$ \\
\hline & Room temperature, humidity and occupancy control & $\checkmark$ & $\checkmark$ & $\checkmark$ & $\checkmark$ & $\checkmark$ \\
\hline & Occupants control & $\checkmark$ & $\checkmark$ & $\checkmark$ & $\checkmark$ & $\checkmark$ \\
\hline & Safe and Secure environment & $\checkmark$ & $\mathrm{x}$ & $\mathrm{x}$ & $\mathrm{x}$ & $\checkmark$ \\
\hline \multirow{8}{*}{ 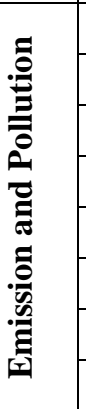 } & Refrigerant ODP and GWP & $\checkmark$ & $\checkmark$ & $\checkmark$ & $\checkmark$ & $\checkmark$ \\
\hline & Refrigerant Leaks & $\checkmark$ & $\mathrm{x}$ & $\checkmark$ & $\mathrm{x}$ & $\checkmark$ \\
\hline & Light and noise and Watercourse pollutions & $\checkmark$ & $\checkmark$ & $\checkmark$ & $\checkmark$ & $\checkmark$ \\
\hline & Legionella & $\checkmark$ & $x$ & $\checkmark$ & $\checkmark$ & $\checkmark$ \\
\hline & Heat Island Effect & $\mathrm{x}$ & $\checkmark$ & $\mathrm{x}$ & $\checkmark$ & $x$ \\
\hline & $\mathrm{CO}_{2}$ emissions & $\checkmark$ & $\checkmark$ & $\checkmark$ & $\checkmark$ & $\checkmark$ \\
\hline & NOx emissions & $\checkmark$ & $x$ & $x$ & $\checkmark$ & $x$ \\
\hline & Fire Risk & $\checkmark$ & $\checkmark$ & $\checkmark$ & $\checkmark$ & $\checkmark$ \\
\hline$\stackrel{9}{9}$ & Site selection and protection & $\checkmark$ & $\checkmark$ & $\checkmark$ & $\checkmark$ & $\checkmark$ \\
\hline
\end{tabular}




\begin{tabular}{|c|c|c|c|c|c|c|}
\hline 苞 & Subcategories & 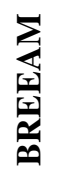 & $\frac{9}{9}$ & 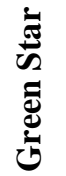 & 空 & ت \\
\hline & Site Re-use & $\checkmark$ & $\checkmark$ & $\checkmark$ & $\mathrm{x}$ & $\checkmark$ \\
\hline & Contaminated Land and Land Ecological Value & $\checkmark$ & $\checkmark$ & $\checkmark$ & $\checkmark$ & $\checkmark$ \\
\hline & Protection of ecological features and Enhance site ecology & $\checkmark$ & $\checkmark$ & $\checkmark$ & $\checkmark$ & $\checkmark$ \\
\hline & Conservation of natural habitats and mitigation ecological impact & $\checkmark$ & $\checkmark$ & $\checkmark$ & $\checkmark$ & $\checkmark$ \\
\hline & Use of Green space & $\checkmark$ & $\checkmark$ & $x$ & $\checkmark$ & $\checkmark$ \\
\hline & Habitat management plan & $\checkmark$ & $\mathrm{x}$ & $\checkmark$ & $\checkmark$ & $\checkmark$ \\
\hline \multirow{7}{*}{ 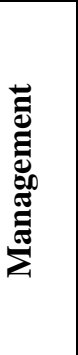 } & Commissioning and environmental management & $\checkmark$ & $\checkmark$ & $\checkmark$ & $\checkmark$ & $\checkmark$ \\
\hline & Tool accredited professional & $\checkmark$ & $\checkmark$ & $\checkmark$ & $x$ & $\checkmark$ \\
\hline & Stakeholder participation & $\checkmark$ & $x$ & $x$ & $x$ & $x$ \\
\hline & Building whole life plan & $\checkmark$ & $x$ & $\checkmark$ & $\checkmark$ & $\mathrm{x}$ \\
\hline & Building occupants guide & $\checkmark$ & $\mathrm{x}$ & $\checkmark$ & $x$ & $\checkmark$ \\
\hline & Construction site impacts & $\checkmark$ & $x$ & $\checkmark$ & $x$ & $\checkmark$ \\
\hline & Maintenance management & $\checkmark$ & $\mathrm{x}$ & $x$ & $\checkmark$ & $\checkmark$ \\
\hline \multirow{6}{*}{ 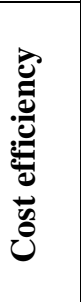 } & Construction cost & $\mathrm{x}$ & $\mathrm{x}$ & $\mathrm{x}$ & $\mathrm{x}$ & $\checkmark$ \\
\hline & Operation and maintenance costs & $\checkmark$ & $\checkmark$ & $x$ & $x$ & $\checkmark$ \\
\hline & Life cycle costing & $\checkmark$ & $x$ & $x$ & $x$ & $\checkmark$ \\
\hline & Building elements cost & $\checkmark$ & $\checkmark$ & $\checkmark$ & $\mathrm{x}$ & $\checkmark$ \\
\hline & Capital cost & $x$ & $x$ & $x$ & $x$ & $\checkmark$ \\
\hline & Real and discounted cost & $\checkmark$ & $x$ & $x$ & $x$ & $x$ \\
\hline \multirow{6}{*}{ 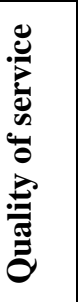 } & Functionality and Usability & $\mathrm{x}$ & $\mathrm{x}$ & $\mathrm{x}$ & $\checkmark$ & $\mathrm{x}$ \\
\hline & System Controllability & $\checkmark$ & $\checkmark$ & $\mathrm{x}$ & $\checkmark$ & $\checkmark$ \\
\hline & Durability and protection & $\checkmark$ & $\mathrm{x}$ & $\mathrm{x}$ & $\checkmark$ & $\checkmark$ \\
\hline & Service Life of Components and reliability & $\checkmark$ & $\mathrm{x}$ & $\mathrm{x}$ & $\checkmark$ & $\mathrm{x}$ \\
\hline & Flexibility and Adaptability & $\mathrm{x}$ & $\mathrm{x}$ & $\checkmark$ & $\checkmark$ & $\checkmark$ \\
\hline & Design flexibility and system renewability & $\mathrm{x}$ & $\mathrm{x}$ & $\mathrm{x}$ & $\checkmark$ & $\checkmark$ \\
\hline \multirow{4}{*}{ 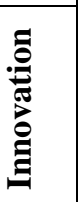 } & Innovation in design & $\checkmark$ & $\checkmark$ & $\checkmark$ & $\mathrm{x}$ & $\checkmark$ \\
\hline & Innovative Strategies \& Technologies & $\checkmark$ & $\checkmark$ & $\checkmark$ & $\mathrm{x}$ & $\checkmark$ \\
\hline & Exemplary Performance & $\checkmark$ & $\checkmark$ & $\mathrm{x}$ & $x$ & $\checkmark$ \\
\hline & Innovating Practice and support innovative culture & $\mathrm{x}$ & $\mathrm{x}$ & $x$ & $\mathrm{x}$ & $\checkmark$ \\
\hline \multirow{4}{*}{ 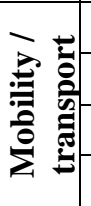 } & Travel plan & $\checkmark$ & $x$ & $\mathrm{x}$ & $x$ & $\checkmark$ \\
\hline & Community Facilities (Proximity to amenities) & $\checkmark$ & $\checkmark$ & $\mathrm{x}$ & $\checkmark$ & $\checkmark$ \\
\hline & Access to public transport and Car parking capacity & $\checkmark$ & $\checkmark$ & $\checkmark$ & $\checkmark$ & $\checkmark$ \\
\hline & Pedestrian and Bicycle facilities and safety & $\checkmark$ & $\checkmark$ & $\checkmark$ & $\checkmark$ & $\checkmark$ \\
\hline
\end{tabular}

\section{Refining the assessment criteria}

In order to refine the assessment criteria considering social cultural and economic situations in Saudi Arabia, eight academics, nine architects and five engineer/project managers were interviewed. Content analysis was utilised to analyse the semi-structured interviews with the 22 Saudi Arabian sustainable building professionals. Table 5 
illustrates the most important assessment criteria that emerged for Saudi sustainable non-residential buildings. In the following Section, the criteria listed in Table 5 will be assigned relative weights and then prioritised.

Table 5 the most important assessment criteria that emerged for Saudi sustainable nonresidential buildings.

\begin{tabular}{|c|c|c|}
\hline Assessment Criteria & Assessment Sub-criteria & $\begin{array}{l}\text { Available in other assessment } \\
\text { tools }\end{array}$ \\
\hline \multirow[t]{4}{*}{ Energy Efficiency } & effective building systems & BREEAM, LEED \\
\hline & efficient management & BREEAM \\
\hline & renewable energy technology & BREEAM, LEED \\
\hline & energy strategies & BREEAM, LEED \\
\hline \multirow{4}{*}{ Water Efficiency } & potable water conservation & BREEAM, LEED \\
\hline & monitoring \& leak detection & BREEAM, LEED \\
\hline & alternative sources & BREEAM \\
\hline & water use & BREEAM, LEED \\
\hline \multirow[t]{4}{*}{ Land and Waste } & pollution \& emission & BREEAM, LEED \\
\hline & construction waste & BREEAM, LEED \\
\hline & operation waste & BREEAM, LEED \\
\hline & sustainable site \& ecology & BREEAM, LEED \\
\hline \multirow{4}{*}{ Materials selection } & responsible sourcing & LEED, CASBEE and Estidama \\
\hline & re-use materials & CASBEE \\
\hline & recycle materials & CASBEE \\
\hline & region materials & LEED and Estidama \\
\hline \multirow[t]{2}{*}{$\begin{array}{l}\text { Indoor Environment } \\
\text { Quality }\end{array}$} & $\begin{array}{l}\text { lighting quality } \\
\text { sounds environment quality } \\
\text { indoor air quality }\end{array}$ & $\begin{array}{l}\text { BREEAM, LEED, Green Star } \\
\text { BREEAM, CASBEE } \\
\text { Common criterion in assessment } \\
\text { tools }\end{array}$ \\
\hline & thermal comfort & $\begin{array}{l}\text { Common criterion in assessment } \\
\text { tools }\end{array}$ \\
\hline \multirow{4}{*}{ Effective Management } & stakeholder participation & BREEAM \\
\hline & building whole life plan & BREEAM \\
\hline & environmental management & BREEAM \\
\hline & facilities management & BREEAM \\
\hline \multirow[t]{3}{*}{ Whole-Life Cost } & construction cost & Estidama \\
\hline & operation cost & BREEAM and Estidama \\
\hline & $\begin{array}{l}\text { disposal \& maintenance cost } \\
\text { building services cost }\end{array}$ & BREEAM and Estidama \\
\hline \multirow[t]{4}{*}{ Quality of Services } & functionality \& usability & CASBEE \\
\hline & durability \& protection & CASBEE \\
\hline & flexibility \& adaptability & CASBEE \\
\hline & reliability & CASBEE \\
\hline \multirow{4}{*}{ Cultural Aspect } & Considering Local Context and character & CASBEE \\
\hline & Contribution to Community & CASBEE \\
\hline & Inspire by Cultural and Regional Precedents & Estidama \\
\hline & Relation with the surrounding environment & Estidama \\
\hline
\end{tabular}

\section{Weighting method - Analytic Hierarchy Process}

This study adopted the Analytic Hierarchy Process (AHP) method to identify the relative importance of environmental assessment criteria through the development of a weighting 
system. Building assessment criteria suitable for Saudi Arabia were identified through data collection, a literature review, a building assessment tool comparison and interviews.

To generate priorities, the AHP method requires four steps: (1) structuring a decision hierarchy, (2) constructing a set of pairwise comparison matrices, (3) checking the consistency of judgments, and (4) prioritizing analysis (Saaty and Sodenkamp, 2010).

Figure 2 illustrates the process used in this study to obtain weights, each step of which is presented in detail in the following sections. It should be noted that inconsistency judgments and incomplete comparisons were excluded from the study during the calculation process.

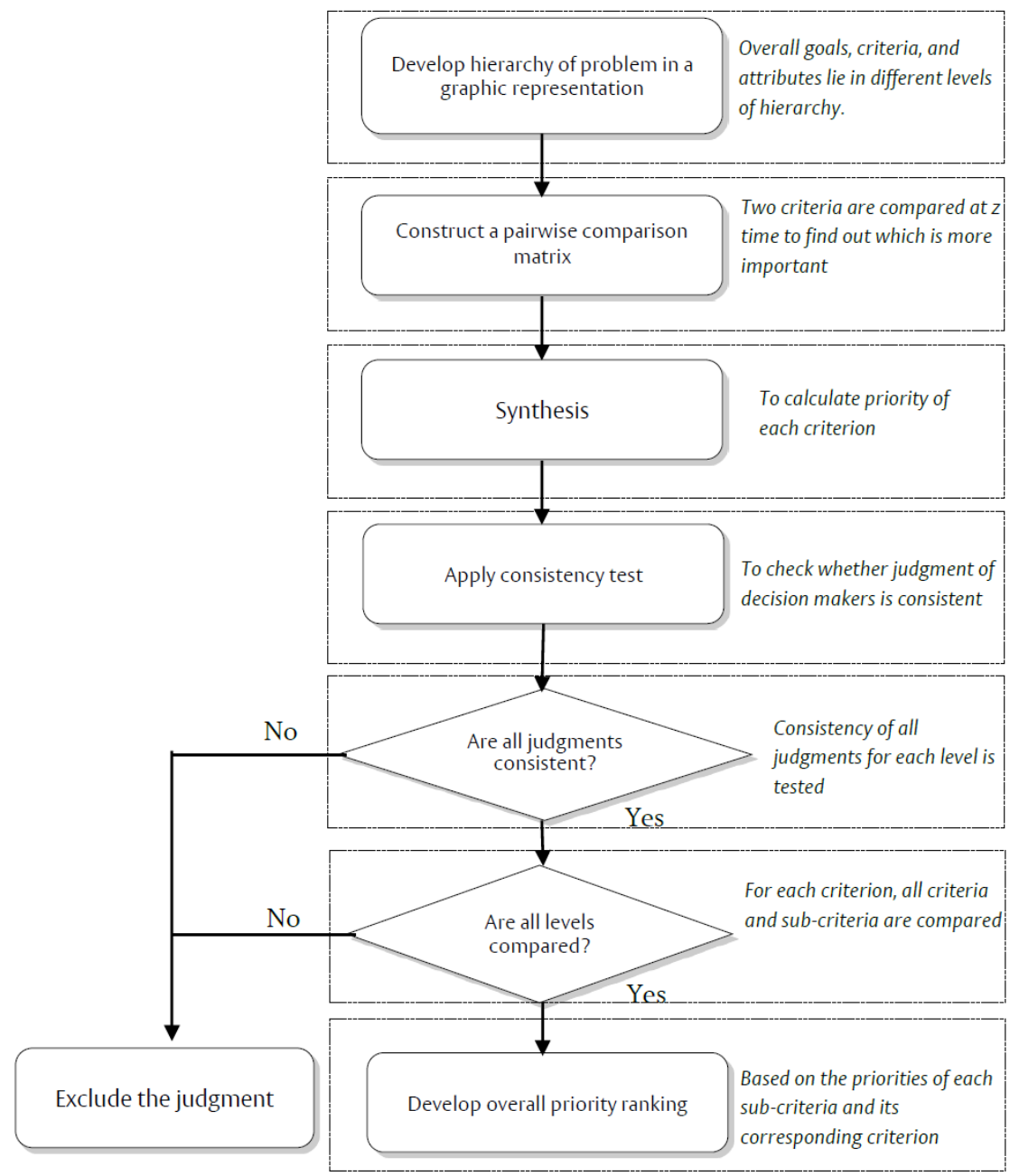

Figure 2 AHP process flowchart, adapted from (Ho, 2008) 


\subsection{Structuring the Assessment Problem and Criteria Selection}

The AHP method allows for the arrangement of potential criteria based on their configuration in a hierarchical structure that descends from the primary goal to criteria and sub-criteria in subsequent levels. Figure 3 presents three levels of the AHP hierarchy with respect to assessing sustainable non-residential buildings in Saudi Arabia. The highest level represents the overall sustainable assessment objective based on the Saudi context. For this study, nine criteria were identified. Moreover, four sub-criteria for each criterion were identified and considered in the assessment. Both these criteria (in bold) and their sub-criteria (in brackets) are situated in the lower levels, and include:

1) Energy efficiency $\left(C_{1}\right)$ [effective building systems $\left(E_{1}\right)$; efficient management $\left(E_{2}\right)$; renewable energy technology $\left(\mathrm{E}_{3}\right)$; energy strategies $\left.\left(\mathrm{E}_{4}\right)\right]$;

2) Water efficiency $\left(\mathrm{C}_{2}\right)$ [potable water conservation $\left(\mathrm{W}_{1}\right)$; monitoring and leak detection $\left(\mathrm{W}_{2}\right)$; alternative sources $\left(\mathrm{W}_{3}\right)$; water use $\left.\left(\mathrm{W}_{4}\right)\right]$;

3) Materials selection $\left(C_{3}\right)$ [responsible sourcing $\left(M_{1}\right)$; re-used materials $\left(M_{2}\right)$; recycled materials $\left(\mathrm{M}_{3}\right)$; regional materials $\left.\left(\mathrm{M}_{4}\right)\right]$;

4) Indoor environmental quality (IEQ) $\left(\mathrm{C}_{4}\right)$ [lighting quality $\left(\mathrm{I}_{1}\right)$; sound environment quality $\left(\mathrm{I}_{2}\right)$; indoor air quality $\left(\mathrm{I}_{3}\right)$; thermal comfort $\left.\left(\mathrm{I}_{4}\right)\right]$;

5) Land and Waste $\left(\mathrm{C}_{5}\right)$ [pollution and emissions $\left(\mathrm{PW}_{1}\right)$; construction waste $\left(\mathrm{PW}_{2}\right)$; operation waste $\left(\mathrm{PW}_{3}\right)$; sustainable site and ecology $\left.\left(\mathrm{PW}_{4}\right)\right]$;

6) Effective management $\left(\mathrm{C}_{6}\right)$ [stakeholder participation $\left(\mathrm{MAN}_{1}\right)$; building whole life plan $\left(\mathrm{MAN}_{2}\right)$; environmental management $\left(\mathrm{MAN}_{3}\right)$, facilities management $\left.\left(\mathrm{MAN}_{4}\right)\right]$;

7) Whole-life cost $\left(\mathrm{C}_{7}\right)$ [construction costs $\left(\mathrm{V}_{1}\right)$; operational costs $\left(\mathrm{V}_{2}\right)$; disposal and maintenance costs $\left(\mathrm{V}_{3}\right)$; building services costs $\left.\left(\mathrm{V}_{4}\right)\right]$;

8) Quality of service $\left(C_{8}\right)$ [functionality and usability $\left(Q_{1}\right)$; durability and protection $\left(Q_{2}\right)$; flexibility and adaptability $\left(\mathrm{Q}_{3}\right)$; reliability $\left.\left(\mathrm{Q}_{4}\right)\right]$;

9) Cultural aspects $\left(\mathrm{C}_{9}\right)$ [consider local context and character $\left(\mathrm{T}_{1}\right)$; contribution to community $\left(\mathrm{T}_{2}\right)$; inspired by cultural and regional precedents $\left(\mathrm{T}_{3}\right)$; relationship with the surrounding environment $\left.\left(\mathrm{T}_{4}\right)\right]$;

These nine criteria and the associated sub-criteria define the suggested boundaries for a proposed sustainable building assessment tool for the Kingdom of Saudi Arabia. 


\begin{tabular}{|c|c|c|c|c|c|c|c|c|}
\hline & & & \multicolumn{3}{|c|}{ Sustainability Assessment } & & & \\
\hline $\begin{array}{c}\text { Energy } \\
\text { Efficiency }(\mathbf{C 1})\end{array}$ & $\begin{array}{c}\text { Water } \\
\text { Efficiency (C2) }\end{array}$ & $\begin{array}{c}\text { Materials } \\
\text { Selection }(\mathbf{C} 3)\end{array}$ & $\begin{array}{c}\text { Indoor } \\
\text { Environment } \\
\text { Quality (C4) }\end{array}$ & $\begin{array}{c}\text { Land and } \\
\text { Waste (C5) }\end{array}$ & \begin{tabular}{|c|} 
Effective \\
Management \\
(C6)
\end{tabular} & $\begin{array}{l}\text { Whole-Life } \\
\text { Value (C7) }\end{array}$ & $\begin{array}{c}\text { Quality of } \\
\text { Service (C8) }\end{array}$ & $\begin{array}{c}\text { Cultural Aspects } \\
\text { (C9) }\end{array}$ \\
\hline $\begin{array}{l}\text { effective building } \\
\text { systems }\left(E_{1}\right)\end{array}$ & $\begin{array}{c}\text { Potable water } \\
\text { Conservation } \\
\text { (W1) }\end{array}$ & $\begin{array}{c}\text { Responsible } \\
\text { Sourcing (M1) }\end{array}$ & $\begin{array}{l}\text { Lighting } \\
\text { Quality (I1) }\end{array}$ & $\begin{array}{c}\text { Pollution \& } \\
\text { Emission (PW1) }\end{array}$ & $\begin{array}{c}\text { Stakeholder } \\
\text { participation } \\
\text { (MAN1) }\end{array}$ & $\begin{array}{l}\text { Construction } \\
\operatorname{cost}(\mathrm{V} 1)\end{array}$ & $\begin{array}{c}\text { Functionality and } \\
\text { Usability (Q1) }\end{array}$ & $\begin{array}{c}\text { Considering Local } \\
\text { Context and } \\
\text { character (T1) }\end{array}$ \\
\hline $\begin{array}{c}\text { efficient } \\
\text { management }\left(E_{2}\right)\end{array}$ & $\begin{array}{c}\text { Monitoring \& } \\
\text { Leak Detection } \\
\text { (W2) }\end{array}$ & $\begin{array}{l}\text { Used of Re- } \\
\text { use Materials } \\
\text { (M2) }\end{array}$ & $\begin{array}{c}\text { Sounds } \\
\text { Environment } \\
\text { Quality (I2) }\end{array}$ & $\begin{array}{l}\text { Construction } \\
\text { waste (PW2) }\end{array}$ & $\begin{array}{c}\text { Building whole } \\
\text { life plan } \\
\text { (MAN2) }\end{array}$ & $\begin{array}{l}\text { Operation cost } \\
\text { (V2) }\end{array}$ & $\begin{array}{l}\text { Durability and } \\
\text { protection }(\mathrm{Q} 2)\end{array}$ & $\begin{array}{l}\text { Contribution to } \\
\text { Community (T2) }\end{array}$ \\
\hline $\begin{array}{l}\text { renewable energy } \\
\text { technology }\left(E_{3}\right)\end{array}$ & $\begin{array}{c}\text { Alternative } \\
\text { Sources for } \\
\text { Irrigation (W3) }\end{array}$ & $\begin{array}{c}\text { Renewable } \\
\text { Materials (M3) }\end{array}$ & $\begin{array}{l}\text { Indoor air } \\
\text { Quality (I3) }\end{array}$ & $\begin{array}{c}\text { Operation } \\
\text { waste (PW3) }\end{array}$ & $\begin{array}{c}\text { Environmental } \\
\text { management } \\
(\mathrm{MAN} 3)\end{array}$ & $\begin{array}{c}\text { Disposal \& } \\
\text { maintenance } \\
\text { cost (V3) }\end{array}$ & $\begin{array}{c}\text { Flexibility \& } \\
\text { Adaptibility (Q3) }\end{array}$ & $\begin{array}{c}\text { Inspire by Cultural } \\
\text { and Regional } \\
\text { Precedents (T3) }\end{array}$ \\
\hline $\begin{array}{l}\text { energy strategies } \\
\qquad\left(\mathrm{E}_{4}\right)\end{array}$ & $\begin{array}{l}\text { Water reuse } \\
\text { (W4) }\end{array}$ & $\begin{array}{c}\text { Region } \\
\text { Materials (M4) }\end{array}$ & $\begin{array}{c}\text { Thermal } \\
\text { Comfort (I4) }\end{array}$ & $\begin{array}{c}\text { Sustainable site } \\
\text { \& Ecology } \\
\text { (PW4) }\end{array}$ & $\begin{array}{l}\text { Facilities } \\
\text { management } \\
\text { (MAN4) }\end{array}$ & $\begin{array}{c}\text { Building } \\
\text { services cost } \\
\text { (V4) }\end{array}$ & Reliability (Q4) & $\begin{array}{l}\text { Relation with the } \\
\text { surrounding } \\
\text { environment (T4) }\end{array}$ \\
\hline
\end{tabular}

Figure 3 Hierarchical structure for proposed sustainable assessment criteria for Saudi Arabia

The next step in determining the weights of the potential criteria was to configure them into a set of pairwise comparison matrices (Saaty, 2008).

In AHP, the priorities are defined through pair-wise comparison of criteria and sub-criteria based on expert judgment. The scales to define theses priorities are provided in Table 6 .

Table 6 the scales to define the preference of Criteria in AHP (Saaty, 1990)

\begin{tabular}{lll}
\hline $\begin{array}{l}\text { INTENSITY OF } \\
\text { IMPORTANCE }\end{array}$ & DEFINITION & EXPLANATION \\
\hline 1 & Equal Importance & $\begin{array}{l}\text { Two activities contribute equally to the objective } \\
\text { Experience and judgment moderately favour one activity } \\
\text { over another } \\
\text { Experience and judgement strongly favour one activity } \\
\text { over another } \\
\text { An activity is strongly favoured and its dominance } \\
\text { demonstrated in practice }\end{array}$ \\
\hline 5 & Eoderate importance & $\begin{array}{l}\text { An activity is extremely favoured and its dominance } \\
\text { demonstrated in practice }\end{array}$ \\
\hline 9 & Very strong importance & Extreme importance \\
\hline $2,4,6,8$ & $\begin{array}{l}\text { Intermediate values between the two } \\
\text { adjacent judgments }\end{array}$ & $\begin{array}{l}\text { If activity } i \text { has one of the above numbers assigned to it when compared with activity } j, \text { then } j \text { has the } \\
\text { reciprocal value when compared with } i .\end{array}$ \\
\hline Reciprocals & & \\
\hline
\end{tabular}


This comparison method helps to identify differences in preferences between criteria (Wang et al., 2009). The priority calculation for each criterion in the hierarchy is applied after all judgments have been made. However, because comparison relies on subjective judgment, some degree of inconsistency may arise. One of the advantages of the AHP method is the ability to check any inconsistencies by computing a consistency ratio for the matrices that measure the degree of consistency among the pairwise comparisons (Ho, 2008). For this study, only consistent pairwise comparisons were used to derive weights. After all pairwise comparisons were completed for all levels with satisfactory consistency, the judgments were then used to determine the relative weights of each criterion and its attributes.

\subsection{Determining Weights for Each Criterion}

This research focused on a subjective weighting method to determine interviewee preference for sustainable building criteria. This study adopted a pairwise comparison approach from the AHP method. Following the AHP subjective weight calculation method, the weight vector is calculated using the principle of the eigenvector. This is introduced as numerical ranking of the criteria that indicates an order of preference among them (Saaty, 2003).

For $n$ criteria, the pairwise comparison matrix A of these criteria is determined as follows:

$$
\begin{aligned}
& \underline{\text { Criteria }} \\
& \begin{array}{lllll}
C_{1} & C_{2} & \ldots & C_{n}
\end{array} \\
& A=\begin{array}{c}
C_{1} \\
C_{2} \\
\vdots \\
C_{n}
\end{array}\left[\begin{array}{cccc}
a_{11}=C_{1} / C_{1} & a_{12}=C_{1} / C_{2} & \ldots & a_{1 n}=C_{1} / C_{n} \\
a_{21}=C_{2} / C_{1} & a_{22}=C_{2} / C_{2} & \ldots & a_{2 n}=C_{2} / C_{n} \\
\vdots & \vdots & \vdots & \vdots \\
a_{n 1}=C_{n} / C_{1} & a_{n 2}=C_{n} / w C_{2} & \ldots & a_{n n}=C_{n} / C_{n}
\end{array}\right]
\end{aligned}
$$

Matrix A represents the pairwise comparison of criteria (C) with respect to each criterion. For matrix A, each element represents the relative preference of one criterion over another. For instance, the element situated in the first row and second column ' $\mathrm{a}_{12}=C_{1} / C_{2}$ ' represents the relative priority (i.e. importance) of the first criterion over the second according to the AHP preference scales. If the first criterions $\left(\mathrm{C}_{1}\right)$ is extremely more important than the second criterion $(\mathrm{C} 2)$, then the relative importance $\left(\mathrm{a}_{12}\right)$ of these two criteria would be represented using the followings equation.

$$
\mathrm{a}_{12}=\left(C_{1} / C_{2}\right)=9
$$

To determine the subjective weight of each criterion, the eigenvalue approach was adopted. The general eigenvalue is obtained through perturbation of the following formulation: 


$$
\left[\begin{array}{cccc}
C_{1} / C_{1} & C_{1} / C_{2} & \ldots & C_{1} / C_{n} \\
C_{2} / C_{1} & C_{2} / C_{2} & \ldots & C_{2} / C_{n} \\
\vdots & \vdots & \vdots & \vdots \\
C_{n} / C_{1} & C_{n} / w C_{2} & \ldots & C_{n} / C_{n}
\end{array}\right] \cdot\left[\begin{array}{c}
w_{1} \\
w_{2} \\
\vdots \\
w_{n}
\end{array}\right]=\lambda_{\max }\left[\begin{array}{c}
w_{1} \\
w_{2} \\
\vdots \\
w_{n}
\end{array}\right]=\left[\begin{array}{c}
b_{1} \\
b_{2} \\
\vdots \\
b_{n}
\end{array}\right]
$$

In equation $3, \mathrm{~W}$ is the vector of weights (eigenvector) $\mathrm{W}=\left(w_{1}, \ldots, w_{n}\right)$ and $\lambda_{\max }$ represents the principle eigenvalue of the pairwise comparison matrix A (Saaty, 1990). To obtain $\lambda_{\max }$ of the matrix A, the following equation can be perturbed:

$\lambda_{\max }=(1 / n) \times \sum_{i=1}^{i=n} \frac{b_{i}}{w_{i}}$

Furthermore, to ensure the consistency of the subjective perception and the accuracy of comparative weights, Saaty (1990) suggests employing a consistency index (CI) and a consistency ratio (CR). In order to define $\mathrm{CI}$ and $\mathrm{CR}$ for pairwise comparison matrix $\mathrm{A}$, the following equations were introduced:

$$
\begin{aligned}
& \mathrm{CI}=\left(\lambda_{\max }-n\right) /(n-1) \\
& \mathrm{CR}=C I /_{R I}
\end{aligned}
$$

where $n$ denotes the number of criteria and RI represents the random consistency index that was introduced by Saaty and Sodenkamp (2010) shown in Table 7.

Table 7 Random Index (RI) values (Saaty and Sodenkamp, 2010)

\begin{tabular}{ccccccccccccccccc}
\hline $\begin{array}{c}\text { Number } \\
\text { of criteria }\end{array}$ & $\mathbf{1}$ & $\mathbf{2}$ & $\mathbf{3}$ & $\mathbf{4}$ & $\mathbf{5}$ & $\mathbf{6}$ & $\mathbf{7}$ & $\mathbf{8}$ & $\mathbf{9}$ & $\mathbf{1 0}$ & $\mathbf{1 1}$ & $\mathbf{1 2}$ & $\mathbf{1 3}$ & $\mathbf{1 4}$ & $\mathbf{1 5}$ \\
\hline R.I. & 0.0 & 0.0 & 0.52 & 0.89 & 1.11 & 1.25 & 1.35 & 1.40 & 1.45 & 1.49 & 1.52 & 1.54 & 1.56 & 1.58 & 1.59 \\
\hline
\end{tabular}

For reliable results, the consistency ration (CR) should not exceed 0.10 , which indicates consistency in the comparison matrix (Saaty, 1990; Saaty and Sodenkamp, 2010; Tzeng and Huang, 2011). In fact, it has been found that if the value of $\mathrm{CR}<0.10$, it means that the weight value calculated in equation 3 is valid and can be utilised whilst when the value of $\mathrm{CR}>0.10$, it is recommended to adjust the pairwise matrix and to modify the element values (Chen et al., 2010). 


\subsubsection{Application}

For the assessment of Saudi sustainable buildings, nine criteria $\left(\mathrm{C}_{1}, \ldots \mathrm{C}_{9}\right)$ were identified in the first hierarchy level Figure 3. Each criterion consists of four sub-criteria, which populate Level 2 (Figure 3). Thus, one 9x9 and nine 4x4 pairwise comparison matrices were made for each questionnaire. Weights were derived through surveying key professionals in the Saudi construction industry. A total of 22 questionnaires were distributed and 18 accurate and complete questionnaires were used for this study, which yielded a total of 180 comparison matrices. MATLAB software was used to calculate vectors relating to eigenvector, eigenvalue, $\mathrm{CI}$ and $\mathrm{CR}$.

To illustrate the process of weighting in detail, a sample of completed questionnaire results is presented in this section. Table 8 presents the pairwise comparison of the energy efficiency criterion as determined by an expert.

Table 8 Weighting factors of energy efficiency sub-criteria

\begin{tabular}{lllllc}
\hline & $\mathrm{E}_{1}$ & $\mathrm{E}_{2}$ & $\mathrm{E}_{3}$ & $\mathrm{E}_{4}$ & $\begin{array}{c}\text { Eigenvector } \\
\text { (Weights) }\end{array}$ \\
$\mathrm{E}_{1}$ & 1.0000 & 1.0000 & 5.0000 & 0.3333 & 0.2387 \\
$\mathrm{E}_{2}$ & 1.0000 & 1.0000 & 3.0000 & 1.0000 & 0.2721 \\
$\mathrm{E}_{3}$ & 0.2000 & 0.3333 & 1.0000 & 0.2000 & 0.0698 \\
$\mathrm{E}_{4}$ & 3.0000 & 1.0000 & 5.0000 & 1.0000 & 0.4194 \\
\hline $\mathrm{CI}=0.0624 ;$ & \multicolumn{5}{c}{$\mathrm{CR}=0.0701 ;$} \\
\hline
\end{tabular}

To compute the subjective weight of energy sub-criteria in this example, the first side of the equation 3 was calculated by utilising the eigenvector (weights) in Table 8.

$$
\left[\begin{array}{cccc}
1 & 1 & 5 & 1 / 3 \\
1 & 1 & 3 & 1 \\
1 / 5 & 1 / 3 & 1 & 1 / 5 \\
3 & 1 & 5 & 1
\end{array}\right] \cdot\left[\begin{array}{c}
0.2387 \\
0.2721 \\
0.0698 \\
0.4194
\end{array}\right]=\left[\begin{array}{c}
0.9996 \\
1.1396 \\
0.2921 \\
1.7566
\end{array}\right]
$$

The CI of the matrix was computed according to equation 5:

$\mathrm{CI}=(4.1873-4) /(4-1)=0.0624$

The CR of the matrix was then computed according to equation 6. Identifying RI is required for the CR equation. In this case, $\mathrm{n}=4$, so according to Table 4 , RI is 0.89 , thus 


$$
\mathrm{CR}=C I / R I=0.0624 / 0.89=0.0701
$$

These results show that for this matrix, CR does not exceed 0.10 , which indicates that the expert's comparisons in Table 8 are consistent to a satisfactory degree. This process was repeated for all the decision matrices in this study.

\subsubsection{Aggregate Individual Judgments}

The last step in the AHP process is to combine individual judgments into a single aggregate group judgment. Research shows that the geometric mean approach is an accurate method of aggregating individual judgments that preserves the reciprocal property of the judgment matrix (Saaty and Sodenkamp, 2010).

The questionnaires yielded 180 comparison matrices. These matrices were categorised into ten group comparison matrices based on criteria such as energy, water and materials. The aggregations of the group comparison matrices are obtained through perturbation of the following formula:

$A_{\text {group }}=\left[\begin{array}{cccc}\sqrt[m]{a_{(11)_{1}} \times a_{(11)_{2}} \times, \ldots, a_{(11)_{m}}}, & \sqrt[m]{a_{(12)_{1}} \times a_{(12)_{2}} \times, \ldots, a_{(12)_{m}}} & \ldots & \sqrt[m]{a_{(1 n)_{1}} \times a_{(1 n)_{2}} \times, \ldots, a_{(1 n)_{m}}} \\ \sqrt[m]{a_{(21)_{1}} \times a_{(21)_{2}} \times, \ldots, a_{(21)_{m}}} & \sqrt[m]{a_{(22)_{1}} \times a_{(22)_{2}} \times, \ldots, a_{(22)_{m}}}, & \ldots & \sqrt[m]{a_{(2 n)_{1}} \times a_{(2 n)_{2}} \times, \ldots, a_{(2 n)_{m}}} \\ \vdots & \vdots & \ddots & \vdots \\ \sqrt[m]{a_{(n 1)_{1}} \times a_{(n 1)_{2}} \times, \ldots, a_{(n 1)_{m}}}, & \sqrt[m]{a_{(n 2)_{1}} \times a_{(n 2)_{2}} \times, \ldots, a_{(n 2)_{m}}}, & \ldots & \sqrt[m]{a_{(n n)_{1}} \times a_{(n n)_{2}} \times, \ldots, a_{(n n)_{m}}}\end{array}\right]$

For this formula, $\mathrm{A}_{\text {group }}$ represents a group comparison matrix for each criterion, $m$ is the number of experts involved in judgments and $a$ is the relative importance between $i$ and $j$ in Matrix $A$, as evaluated by an expert. Each row of Matrix $\mathrm{A}_{\text {group }}$ identifies the ratios of the weights of each criterion with respect to all others (Saaty, 1990). CI, CR and $\lambda_{\max }$ for all aggregation metrics were also determined.

\subsection{Results}

The results of the combined Saudi sustainability practioners' judgments are presented in Table 9, and shows that the water efficiency and energy efficiency criteria represent the highest priority criteria for Saudi sustainable non-residential building assessment at 0.27 and 0.24 , respectively. Meanwhile, the quality of services and culture aspect criteria represent the lowest weights, at 0.04 and 0.03 , respectively. It is also noteworthy that the IEQ and materials selection criteria have similar weights, with a small difference between them of about 0.09 . 
The differences in criteria weights divides them into four groups: G1 (Water and Energy), G2 (Materials and IEQ), G3 (Effective Management, Land and Waste, and Whole-life cost) and G4 (Quality of services and cultural aspects). Figure 4 shows the approximate weights for each hierarchical level of assessment of non-residential sustainable construction in Saudi Arabia. It can be seen that the difference between group 1 and the other groups is significant compared with the differences between other groups' weights, which indicate the importance of G1 for Saudi Arabia. Also, the consistency ratio of the matrix $(\mathrm{CR}=0.0095)$ illustrates the consistency of the judgments obtained. Therefore, the weights of the primary sustainable buildings criteria are considered satisfactory for the Saudi Arabian context. Table 10 summarizes the values for the assessment categories, groups and criteria. It is worth noting that environmental aspects account for the largest proportion of the total assessment weight.

Table 9 Group comparison matrix of criteria for Level 1 of the hierarchy

\begin{tabular}{|c|c|c|c|c|c|c|c|c|c|c|}
\hline & $C_{1}$ & $C_{2}$ & $C_{3}$ & $\mathrm{C}_{4}$ & $C_{5}$ & $\mathrm{C}_{6}$ & $C_{7}$ & $\mathrm{C}_{8}$ & $C_{9}$ & $\begin{array}{c}\text { Eigen- } \\
\text { vector } \\
\text { (Weights) }\end{array}$ \\
\hline $\begin{array}{l}\text { Energy } \\
\text { Efficiency }\end{array}$ & 1.0000 & 0.7627 & 2.9855 & 2.9542 & 4.2601 & 3.6445 & 3.1713 & 4.5253 & 6.1607 & 0.2429 \\
\hline $\begin{array}{l}\text { Water } \\
\text { Efficiency }\end{array}$ & 1.3110 & 1.0000 & 3.4392 & 3.0876 & 3.7116 & 3.3254 & 4.3933 & 5.3827 & 6.2209 & 0.2715 \\
\hline $\begin{array}{l}\text { Materials } \\
\text { Selection }\end{array}$ & 0.3349 & 0.2908 & 1.0000 & 1.0605 & 1.3652 & 1.3493 & 1.4051 & 3.2746 & 3.5194 & 0.1003 \\
\hline IEQ & 0.3385 & 0.3239 & 0.9429 & 1.0000 & 1.6632 & 1.7433 & 1.9481 & 1.9537 & 3.1330 & 0.1012 \\
\hline $\begin{array}{l}\text { Land and } \\
\text { Waste }\end{array}$ & 0.2347 & 0.2694 & 0.7324 & 0.6012 & 1.0000 & 0.8513 & 1.0184 & 1.5683 & 2.3771 & 0.0667 \\
\hline $\begin{array}{l}\text { Effective } \\
\text { Management }\end{array}$ & 0.2744 & 0.3007 & 0.7411 & 0.5736 & 1.1746 & 1.0000 & 1.0968 & 1.7689 & 2.9565 & 0.0746 \\
\hline $\begin{array}{l}\text { Whole-life } \\
\text { cost }\end{array}$ & 0.3154 & 0.2276 & 0.7117 & 0.5133 & 0.9819 & 0.9117 & 1.0000 & 1.4200 & 2.0795 & 0.0649 \\
\hline $\begin{array}{l}\text { Quality of } \\
\text { Service }\end{array}$ & 0.2210 & 0.1858 & 0.3054 & 0.5118 & 0.6376 & 0.5653 & 0.7042 & 1.0000 & 2.0560 & 0.0469 \\
\hline $\begin{array}{l}\text { Culture } \\
\text { Aspects }\end{array}$ & 0.1623 & 0.1608 & 0.2841 & 0.3192 & 0.4207 & 0.3382 & 0.4809 & 0.4864 & 1.0000 & 0.0310 \\
\hline $\mathrm{Cl}=0.0138$ & & $C R=0.0$ & & $\lambda_{\max }$ & 105 & & & & & 1.0000 \\
\hline
\end{tabular}




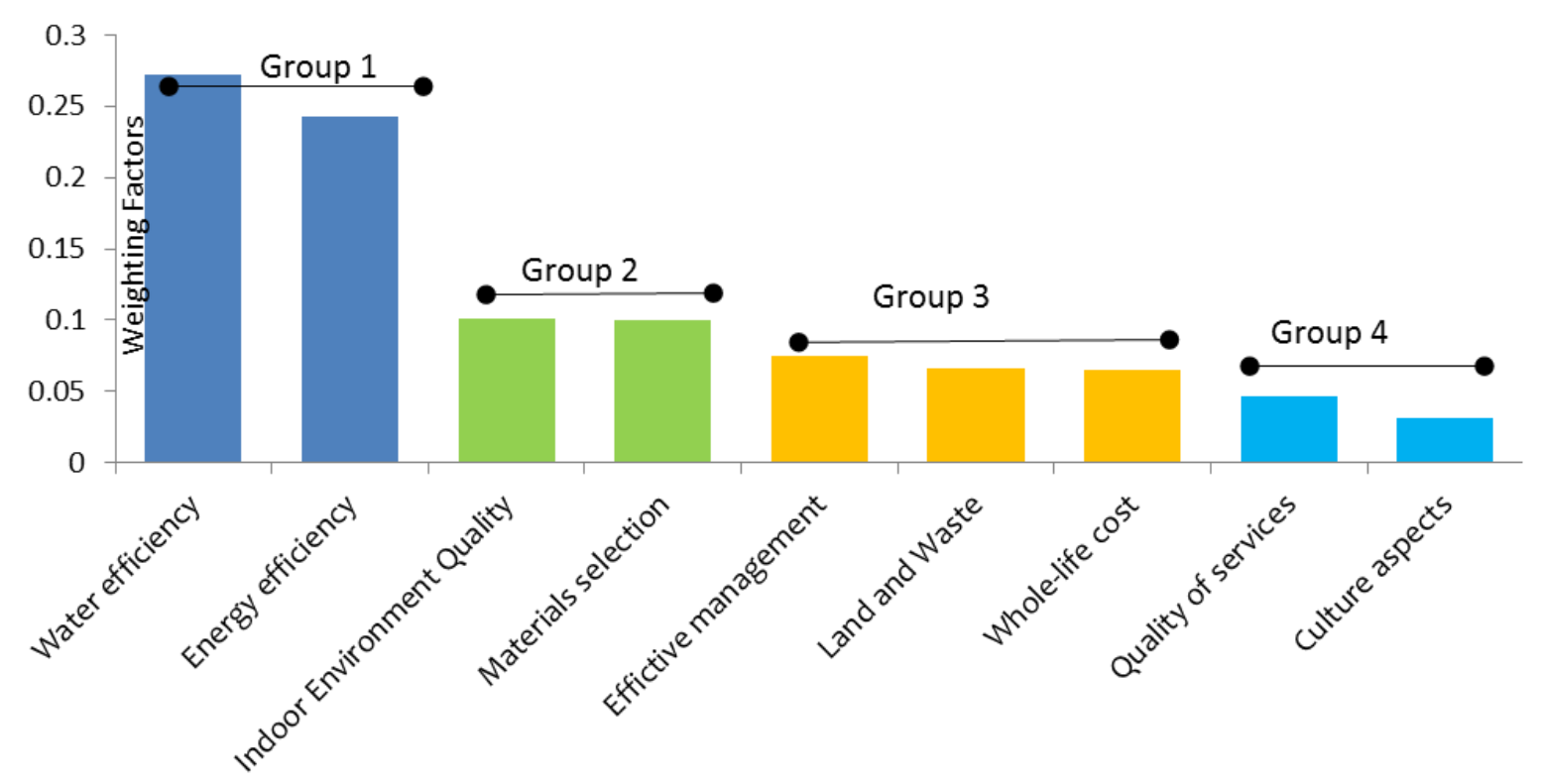

Figure 4 Weights of the primary criteria for sustain able non-residential building assessment in Saudi Arabia

Table 10 Summary of criteria weights and priorities for assessing sustainable non-residential buildings in Saudi Arabia

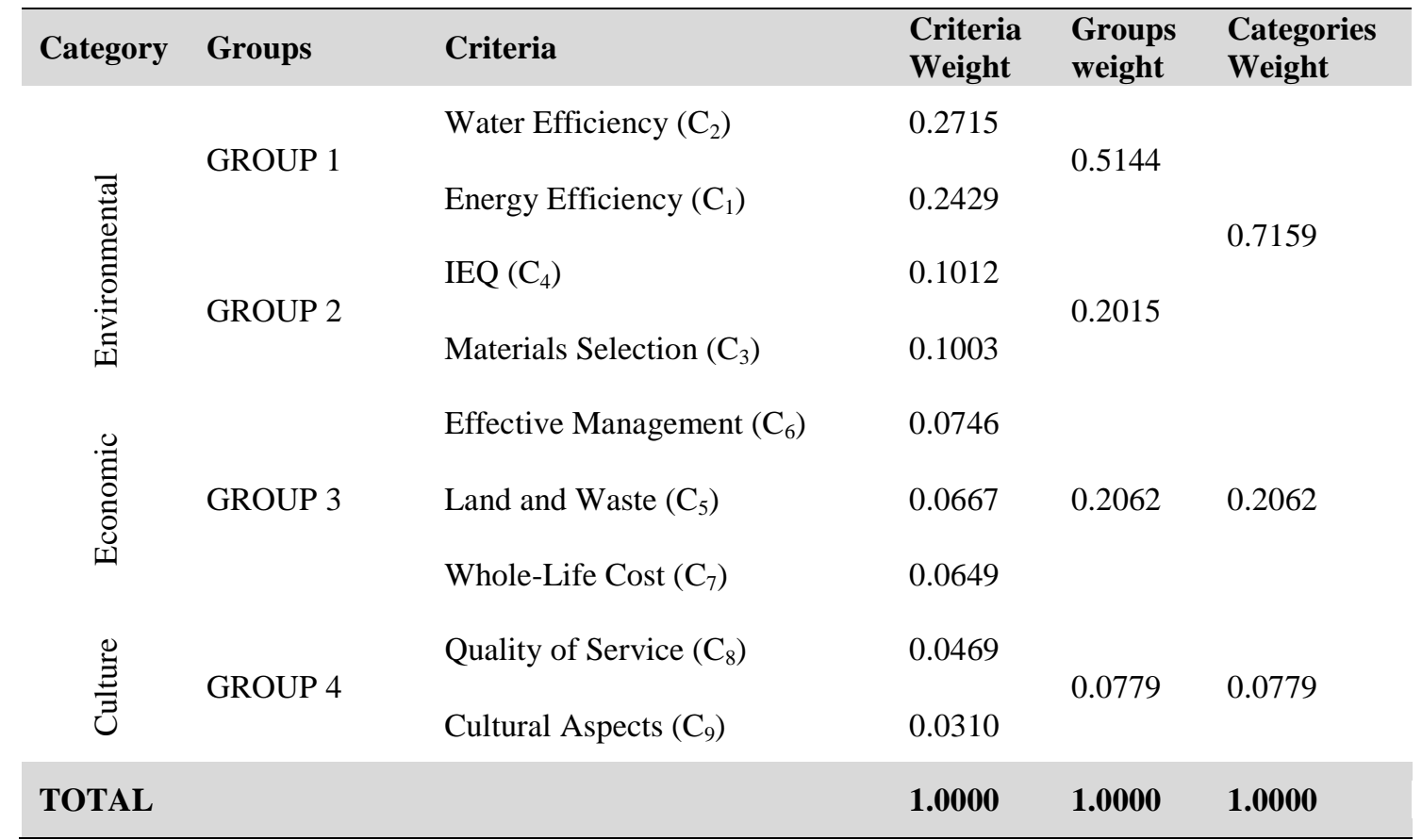

Figure 5 illustrates both the hierarchy and weight associated with each criteria and subcriterion included in the assessment. Thermal comfort exhibited the highest sub-criterion value, 0.46, and is thus considered the most important sub-criterion within the sustainability assessment framework. The sub-criterion project relations with the surrounding environment (T4) weighted at 0.36 , ranks as the second most important in the assessment system. 


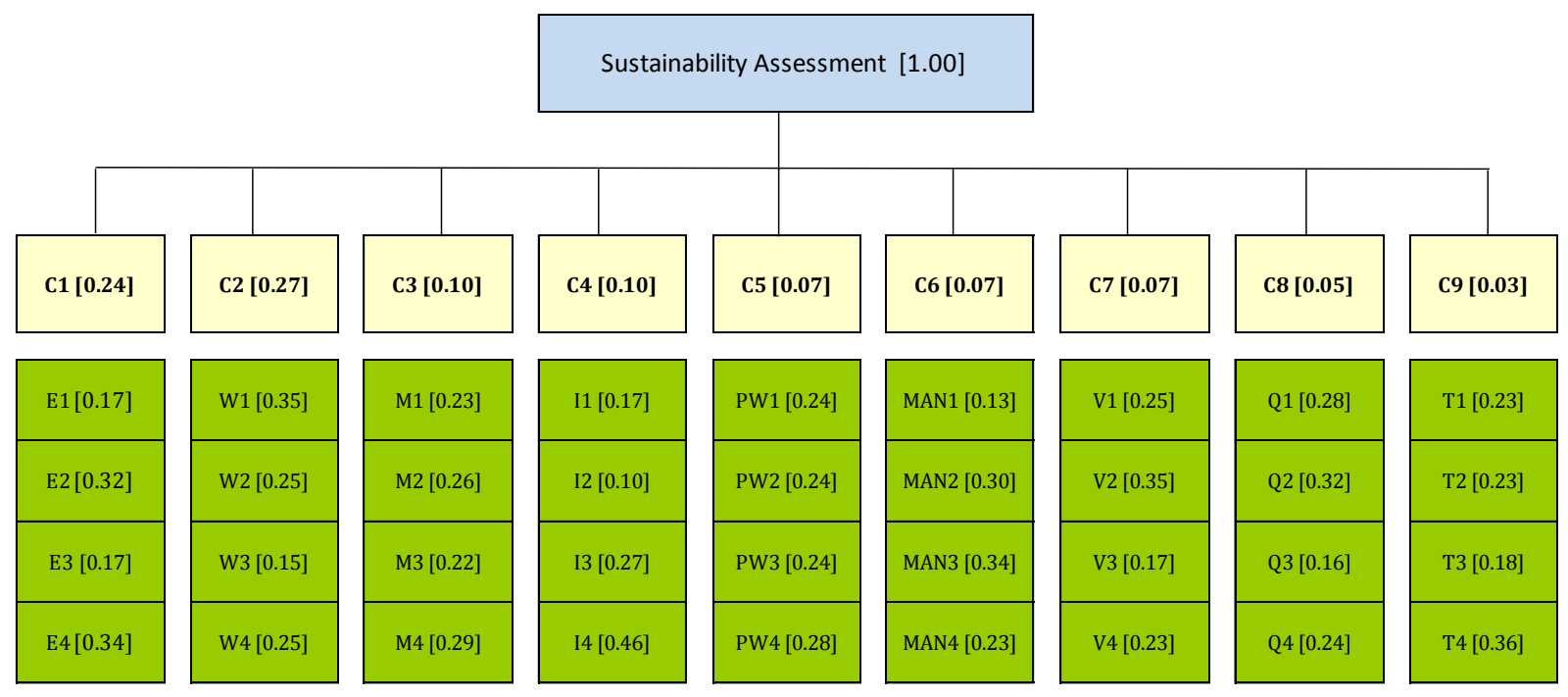

Figure 5 Relative criteria weights for the proposed sustainable non-residential building assessment tool

\section{Discussion}

This study created a weighting framework for sustainable building assessment criteria for non-residential buildings in Saudi Arabia. The AHP method was used to establish relative weights for potential assessment criteria and their associated sub-criteria. A strong relationship between local context and sustainable assessment methods has been reported in the literature (Ding, 2008; Reed et al., 2009; Chandratilake and Dias, 2013). This relationship is comprised of various factors, such as climatic conditions, topographic features, material selection and building stock, which have been considered in this study.

In this study, the weighting results determined the priority which each sustainability aspect holds in Saudi Arabia (Table 10). In addition, the results categorise the criteria based on their calculated weights, which reveal that environmental aspects occupy the highest priority. The group weights in Table 10 were assessed to identify three different priority ranks for the assessment criteria, listed as follows:

- Significantly important (S): The total weights of a group of included criteria fit the equation $(\mathrm{S} \geq 0.3)$;

- Highly important $(\mathrm{H})$ : The total weights of a group of included criteria fit the equation $(\mathrm{H} \geq 0.2)$

- Important (M): The total weights of a group of included criteria fit the equation $(\mathrm{M} \leq$ $0.1)$. 
As Table 10 shows, the first group (G1) falls under the S priority ranking. The G2 and G3 groups both fell under the $\mathrm{H}$ priority, whilst the G4 group fell under the M ranking. These priority ranks helped to identify the importance of economic aspects, which were ranked as H. This grouping step helps to explain the different priorities inherent in assessment criteria for the Saudi Arabian context.

The results indicate that water efficiency accounts for the largest distribution of priority weighting for Saudi Arabian non-residential buildings. This important fact is clearly due to the effect of Saudi Arabia's arid climate. Meanwhile, energy was also indicated as a significant issue in Saudi Arabia from different perspectives. It can be noted that these factors were emphasised by Saudi experts with respect to reducing the consumption of both water and energy in order to conserve these natural resources.

For the second level of the hierarchy, a number of sub-criteria within each criterion were assigned higher weights. As shown Figure 5, thermal comfort arose as the sub-criterion exhibiting the highest weight relative to other sub-criteria at the same level. The emphasis on this sub-criterion is most likely attributable to Saudi Arabia's arid climate, which underscores the significant role of HVAC systems in regulating the building environment to provide comfort (Fasiuddin and Budaiwi, 2011). Furthermore, for the materials selection criterion, emphasis was placed on the use of regional materials, such as concrete and rock, rather than recycled materials, which reflects the demand for local materials. Finally, these results suggest an integrated relationship between material selection and IEQ, as materials can significantly influence IEQ (Venkatarama Reddy and Jagadish, 2003).

Ding (2008) suggested that financial considerations can be as important as environmental factors in assessing environmental concerns with respect to sustainable construction. Despite this fact, the management, land and waste, and whole-life cost criteria received less weight relative to the water and energy criteria. A notable weight cost appears by grouping these criteria under the economic category (Table 10). It should be noted that attention is given to the operational stage (V2) of a building's life cycle with respect to the whole-life cost criterion (Figure 5). Meanwhile, a smaller weight was assigned to the construction phase (V1) than the design phase. Nevertheless, the construction (PW2) and operation (PW3) phases have also been identified within the land and waste criterion, but they were assigned almost identical weights (Figure 5). These differences in prioritising the consideration of building phases reflect the level of understanding of sustainability in the Saudi building 
industry, as well as regional demands. Clearly, for Saudi sustainable construction, the building operation phase is key from both an environmental and economic perspective.

Durability and a project's relationship with its surrounding environment (T4) emerged as an important sub-criteria within the culture category (Figure 5). In fact, due to Saudi Arabia's harsh climate, durability is demanded in sustainable Saudi construction. Also evident was a strong link between durability and materials selection to achieve cost reductions in the building operation phase and to improve building performance (John, 2011; Goh and Rowlinson, 2013).

Finally, the overall criteria weights were calculated based on consistent judgments that reflect current professional understanding of sustainable non-residential construction for the Saudi context.

In this work, criteria weights for four systems (BREEAM, LEED, Green Star and Estidama) were compared based on the weights of the Saudi Assessment Criteria of sustainable buildings for non-residential purposes (SAT). It is difficult to calculate the value of each criterion in CASBEE because its calculations are based on the final score (Kawazu et al., 2005b; Reed et al., 2009). In Table 11, the weights associated with the four sustainable assessments are illustrated and the corresponding criteria are categorised into SAT groups. The innovation criterion for each system has been included in the category of whole-life cost, which is not available in these systems. Furthermore, the SAT's quality of service criterion has no corresponding criteria in the other methods.

Table 11 Comparison of different tools' criteria weighting

\begin{tabular}{lccccc}
\hline & BREEAM & LEED & Green Star & Estidama & SAT \\
Energy Efficiency & 0.19 & 0.33 & 0.21 & 0.24 & 0.24 \\
Water Efficiency & 0.05 & 0.10 & 0.09 & 0.24 & 0.27 \\
\hline IEQ & 0.14 & 0.14 & 0.20 & 0.20 & 0.10 \\
Materials Selection & 0.13 & 0.14 & 0.18 & 0.15 & 0.10 \\
\hline Effective Management & 0.12 & $\mathrm{XXX}$ & 0.09 & $\mathrm{XXX}$ & 0.07 \\
Land and Waste & 0.28 & 0.24 & 0.20 & 0.06 & 0.07 \\
Whole-Life Cost & 0.09 & 0.05 & 0.03 & 0.01 & 0.07 \\
Quality of Service & $\mathrm{XXX}$ & $\mathrm{XXX}$ & $\mathrm{XXX}$ & $\mathrm{XXX}$ & 0.05 \\
\hline Cultural Aspects & $\mathrm{XXX}$ & $\mathrm{XXX}$ & $\mathrm{XXX}$ & 0.07 & 0.03 \\
\hline
\end{tabular}


Table 11 shows that the energy efficiency criterion weights for the selected assessment methods vary, which is considered of global environmental concern. However, a different perspective than an environmental one has influenced the energy efficiency criterion in Saudi Arabia, namely economic resources. For the LEED system, the emphasis is placed on energy, which gives it the highest weight among the tools. Attia (2013) mentioned that many LEED indicators have been found inapplicable in the Saudi context due to differences in the consideration of sustainability perspectives. These differences have led to an unjustified reduction of weights, which has affected the efficiency of the criterion.

It is interesting to note that the water efficiency, land and waste criteria values for SAT and Estidama are quite close. Likewise, the differences in the weights of those criteria in SAT and Estidama with other assessment methods (BREEAM, LEED and Green Star). For instance, BREEAM, LEED and Green Star weight water efficiency criterion lower than Estidama and SAT. As discussed earlier, Due to the environmental conditions water criteria should be given the highest priority; however, most assessment schemes focus on energy efficiency (Lee, 2013). On the other hand, the land and waste criterion is weighted relatively low for SAT and Estidama, but significantly higher for BREEAM, LEED and Green Star.

The weight of the whole-life cost criterion is considered differently in all assessment methods (Table 11). BREEAM and SAT exhibit the highest weights in comparison with other assessment methods, at 0.09 and 0.07, respectively. Meanwhile, Estidama shows the lowest weight for this criterion at 0.01 (Table 11). However, the cultural aspect criterion is only found in Estidama and SAT, which shows the importance of local context in Arabian countries. Considering these differences in criterion weight and priority could enhance assessment efficiency in Saudi Arabia. Moreover, this comparison highlights a number of differences inherent in considering building sustainability between developed and developing countries, which may positively affect the result of the assessment methods.

\subsection{Saudi Sustainable Assessment Criteria Framework}

In this study a new criteria framework was developed according to the research design discussed in Section 3. It demonstrates the sustainable building assessment criteria according to their respective weights and priorities for the Saudi Arabia context (Figure 6). 


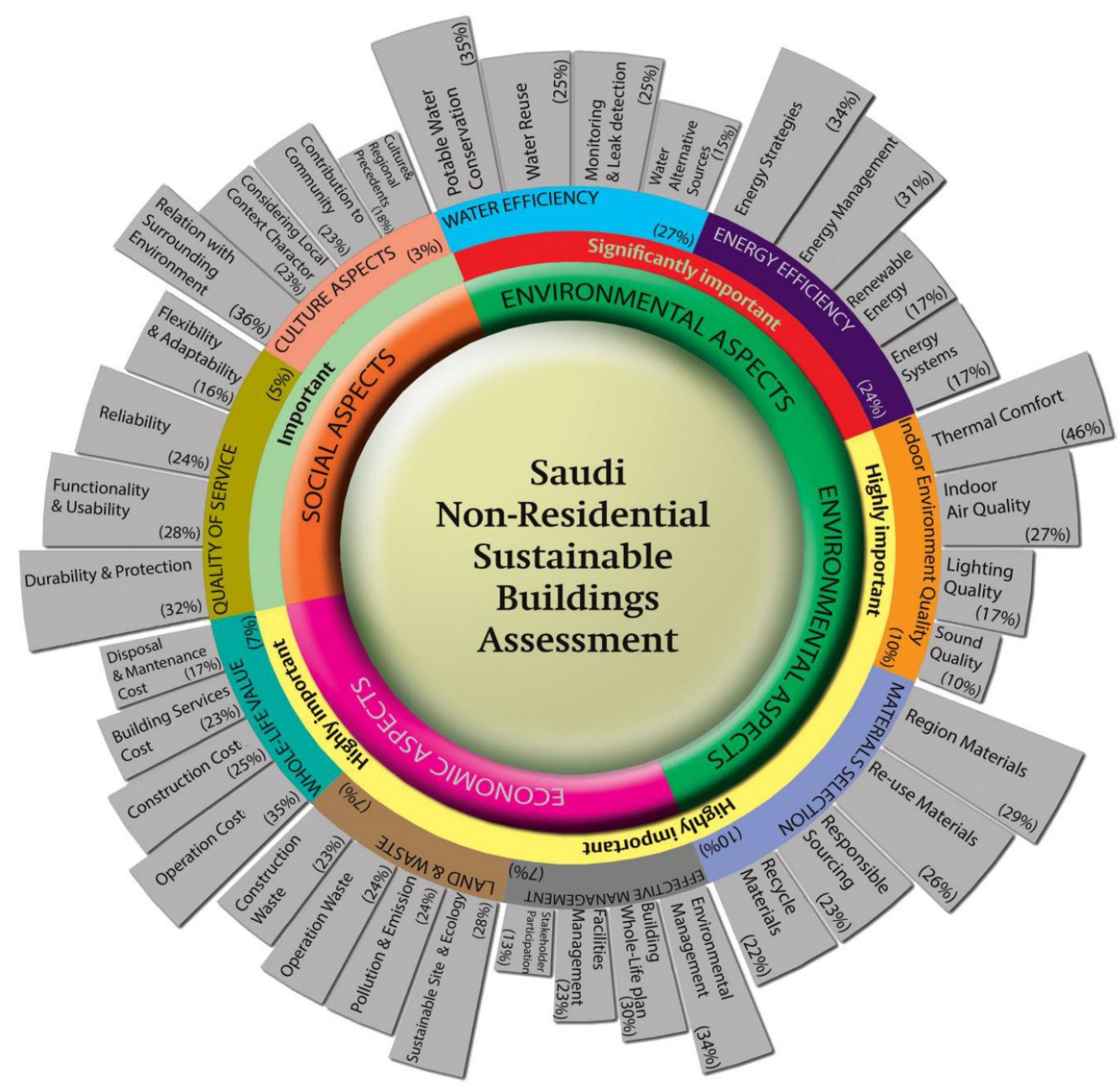

Figure 6 the Saudi Arabian non-residential sustainable buildings assessment criteria framework

In total, the assessment framework identifies nine main criteria and 36 sub-criteria for measuring the performance of sustainable non-residential buildings in Saudi Arabia (Figure $6)$.

The AHP results show that in Saudi Arabia, access to water is the most important issue for sustainable building assessment criteria due to its relationship to human health and the Kingdom's arid climate.

Water is also linked with energy consumption in Saudi Arabia due to the need for water desalination. Water recycling and leak detection are the most effective options for conserving water in Saudi non-residential buildings, with each accounting for $25 \%$ of the total water criteria weight (Figure 6). 
In contrast to water supplies, energy resources are abundant in Saudi Arabia, as it is one of the world's main oil exporting countries. The comparison of energy criteria across different tools suggests that energy performance can be measured as annual energy emissions, annual energy costs or annual energy consumption. However, each of these methods is suitable only for indicating energy performance for the local context in which each tool was developed. As reduced energy consumption is a key concern for Saudi Arabia annual energy consumption stands as the most appropriate measurement approach for assessing energy performance in Saudi non-residential buildings.

Despite the fact that IEQ and material selection criteria exhibited similar weights in the Saudi context, materials selection can also significantly influence IEQ (Venkatarama Reddy and Jagadish, 2003). On the other hand, research suggests that there is a significant relationship between material selection and reduced energy consumption. In addition, materials selection criteria can also have dual influences on building performance. In Saudi Arabia, experts emphasise local materials as the most important sub-criterion within materials selection criteria. Presumably, this importance is due to Saudi Arabia's harsh climate, which affects building life expectancy. Furthermore, this emphasis by Saudi experts on using local materials is also an attempt to create new job opportunities in the construction market.

Economic considerations comprise a large share of sustainable building assessment criteria. However, the priorities of the criteria included in these considerations vary across assessment tools. For instance, management and cost efficiency criteria are not directly represented in tools such as LEED and Estidama, but rather are included as sub-criteria within other criteria, such as energy and materials. Meanwhile, management is a main category in the BREEAM and Green Star systems. This variation in criteria priorities and aspects results in part from differences in the framing of sustainability and in regional priorities.

Additionally, economic considerations are not only limited to specific criteria, but rather contribute to the overall development of assessment tool criteria. For example, one of the main concerns linked to energy issues in Saudi Arabia lies in reducing oil consumption to secure the availability of the country's main economic resource. Therefore, reducing energy consumption achieves the dual objectives of environmental protection and economic security. Furthermore, industry activities contribute to the prioritisation of assessment criteria, such as sustainable building materials, lighting and HVAC systems, through concerns over product availability and cost. 
The AHP results show that reducing costs during a building's operational phase is the most important sub-criterion contained within whole-life cost category. This sub-criterion constitutes $35 \%$ of the total weight of whole-life cost criterion, as shown in Figure 6 This finding is supported by the emphasis of Saudi experts regarding the importance of considering building life expectancy, i.e. short or long term schemes. This emphasis is one of the trends suggested for promoting sustainable construction in Saudi Arabia. This trend is shown clearly in the assessment framework which allocates $30 \%$ of the total weight of its effective management criterion to the building whole-life plan sub-criterion.

Figure 6 shows that one noteworthy feature of the Saudi assessment criteria framework is its consideration of land and waste criteria as economic aspects, not environmental aspects. This difference stems from the absence of the effects of these issues in Saudi Arabia to date, as disposal of construction waste is achieved through landfill burial, due to ample land availability. However, due to increasing population, industrial growth and the construction boom, this issue will most likely become a significant problem in the future.

The consideration of social factors is a key element in advancing sustainable building construction in Saudi Arabia that has contributed considerably to developing the criteria framework for this study. For example, transportation criteria are addressed differently in other assessment tools. However, in Saudi Arabia this criterion is inappropriate due to its inapplicability to the region's climate and social life style. As a result, this criterion was replaced by cultural sub-criteria that increase the applicability of the assessment criteria. Also, this adjustment contributes to reducing the unjustified loss of weighting due to inapplicable or inappropriate criteria (Attia, 2013). In addition, a consideration of Saudi Arabia's culture could play an essential role in achieving the social dimensions of assessment criteria and promoting sustainability in the region.

This study identified certain criteria as social aspects in the Saudi context in regard to sustainable buildings. As shown in Figure 6, two criteria represent social factors in the Saudi construction industry: quality of services and cultural aspects. In fact, all assessment tools aim to promote sustainable construction by increasing their number of sub-criteria, such as durability and reliability. However, this study shows that CASBEE is the only tool that comprehensively incorporates quality of services criteria, whilst other tools include a few sub-criteria to be applied under other criteria. In addition, local context plays an important role in identifying any sub-criteria required to achieve quality of services criteria. 
In this study, the 'quality of services' and cultural aspects are identified as culture related criteria and they constitute 5\% and 3\% of total weights respectively. Review of the weights allocated in other assessment tools (Table 11) revealed that cultural aspects has been also weighted relatively low at 7\% in Estidama (AUPC, 2010b). However, regardless of relatively lower weights for these two sub criteria, recognition of social aspects within the context of sustainable assessment schemes is a step forward toward integration of social themes and cultural aspects to the environmental assessment frameworks. In addition, according to Rahardjati et al (2010), culture should be considered in developing any Saudi building assessment tool.

\section{Conclusions}

Nine criteria and 36 sub-criteria were defined in this study for inclusion as the most appropriate assessment criteria for sustainable non-residential construction in Saudi Arabia. These criteria include water efficiency and energy efficiency, IEQ, materials selection, effective management, land and waste, whole-life cost, quality of service and cultural aspects. It was observed that these identified criteria closely resemble those of international tools such as BREEAM and LEED, but differed somewhat in their priorities due to their consideration of the Saudi context.

The results show that environmental factors are the most important aspect of sustainability in Saudi Arabia, capturing $72 \%$ of total assessment weight. This includes the greatest weighting criteria, water and energy, which represented $51 \%$ of the total assessment criteria weight. The water criterion showed the greatest weight in the assessment of non-residential sustainable building in Saudi Arabia, which in turn contributed significantly to raising the environmental aspect weight value for this research. The energy criteria exhibited less weight than the water criteria, but their priority is currently the same in Saudi Arabian non-residential sustainable construction. Results indicate that Saudi Arabia's relatively harsh climate is the link between IEQ $\left(\mathrm{I}_{4}\right)$, materials selection $\left(\mathrm{M}_{4}\right)$ and durability $\left(\mathrm{Q}_{2}\right)$ in sustainable non-residential construction. Finally, results show that the difference in criteria priorities, particularly with respect to Land and waste criteria, indicates a priority variation between regions due to their local context.

To expand the assessment method proposed in this study, the next phase of this work could involve conducting a broader survey both in terms of category and number of participants. Including the building occupants will bring further insight to analyse the robustness of the 
proposed assessment approach. In addition, further analysis of the feedbacks received from occupants can be used to extend the scope of criteria and make it ready to be implement as a tailor-made certification system designed particularly for the Saudi Arabia construction industry.

\section{Acknowledgments}

The Authors are grateful for the funding of this work by Ministry of Education of the Saudi Arabian Cultural Bureau in London.

\section{Reference list}

Abdalla, G., Maas, G., Huyghe, J., Oostra, M. 2011. 'Criticism on environmental assessment tools', 2nd International Conference on Environmental Science and Technology, IPCBEE.

Ali, H., Al Nsairat, S., 2009. Developing a green building assessment tool for developing countries - Case of Jordan. Building and Environment. 44(5), 1053-1064.

Alwaer, H., Clements-Croome, D., 2010. Building sustainability awards 2010- sustainable innovation of the year. Hilson Moran.

Alyami, S. H., Rezgui, Y., 2012. Sustainable building assessment tool development approach. Sustainable Cities and Society. 5(0), 52-62.

Attia, M. K. M., 2013. LEED as a tool for enhancing affordable housing sustainability in Saudi Arabia: The case of Al-Ghala project. Smart and Sustainable Built Environment. 2(3), 224-250.

AUPC (2010a) Pearl Building Rating System for Estidama: Design and Construction (1). AUPC, 2010b. Pearl building: Guide for consultant. Abu Dhabi Urban Planning Council. BP, 2014. BP statistical review of world energy june 2014. 63rd edn. BP p.l.c, London. BRE (2011) BREEAM New Construction: Non- Domestic Buildings (Technical Manual SD5073-2.0:2011). Watford.

BRE 2015. Background to the Green Guide to Specification: Methodology and Sponsors. Available at: Building Research Establishment Ltd.

http://www.bre.co.uk/greenguide/page.jsp?id=2069 (Accessed: 20.11 ).

Chandratilake, S. R., Dias, W. P. S., 2013. Sustainability rating systems for buildings: Comparisons and correlations. Energy. 59(0), 22-28. 
Chen, Y., Yu, J., Khan, S., 2010. Spatial sensitivity analysis of multi-criteria weights in GISbased land suitability evaluation. Environmental Modelling \& Software. 25(12), 1582-1591.

Cole, R., 1998. Emerging trends in building environmental assessment methods. Building Research \& Information. 26(1), 3-16.

Cole, R., 1999. Building environmental assessment methods: clarifying intentions. Building Research \& Information. 27(4-5), 230-246.

Darus, Z. M., Hashim, N. A., Salleh, E., Haw, L. C., Rashid, A. K. A., and Manan, S. N. A. 2009. 'Development of rating system for sustainable building in Malaysia', WSEAS Transactions on Environment and development. pp. 260-272.

Ding, G., 2008. Sustainable construction-The role of environmental assessment tools. Journal of Environmental Management. 86(3), 451-464.

Dirlich, S., 2011. A comparison of assessment and certification schemes for sustainable building and suggestions for an international standard system. IMRE Journal. 5(1), 112.

Dixon, T., Colantonio, A., Shiers, D., Gallimpre, P., Reed, R., Wilkinson, S., 2007. A green profession: An audit of sustainability tools, techniques and information for rics members,. Royal Institution of Chartered Surveyors.

Fasiuddin, M., Budaiwi, I., 2011. HVAC system strategies for energy conservation in commercial buildings in Saudi Arabia. Energy and Buildings. 43(12), 3457-3466.

Forsberg, A., Von Malmborg, F., 2004. Tools for environmental assessment of the built environment. Building and Environment. 39(2), 223-228.

Franzoni, E., 2011. Materials Selection for Green Buildings: which Tools for Engineers and Architects? Procedia Engineering. 21(0), 883-890.

GBCA 2012. Green Star overview. Available at: Green Building Council Australia ,http://www.gbca.org.au/green-star/green-star-overview/ (Accessed: 06.01).

Goh, C. S., Rowlinson, S. 2013. 'The roles of sustainability assessment systems in delivering sustainable construction', Procs 29th Annual ARCOM Conference. Reading, UK. Association of Researchers in Construction Management, pp. 1363-1371.

GORD, 2012. GSAS/QSAS Technical Guide. Gulf Organization for Research \& Development.

Haapio, A., Viitaniemi, P., 2008a. A critical review of building environmental assessment tools. Environmental Impact Assessment Review. 28(7), 469-482. 
Ho, W., 2008. Integrated analytic hierarchy process and its applications - A literature review. European Journal of Operational Research. 186(1), 211-228.

John, V. M. 2011. 'Sustainable Construction, Innovation and Durability: Trends and Research Needs', International Conference on Durability of Building Materials and Components. Porto, Portugal, April 12th - 15th. p. 7.

Kajikawa, Y., Inoue, T., Goh, T., 2011. Analysis of building environment assessment frameworks and their implications for sustainability indicators. Sustainability Science. 6(2), 233-246.

Kawazu, Y., Shimada, N., Yokoo, N., Oka, T. (2005a) Proceedings of the Sustainable Building Conference (SB05), Tokyo, Japan.

Kawazu, Y., Shimada, N., Yokoo, N., Oka, T. 2005b. 'Comparison of the assessment results of BREEAM, LEED, GBTool and CASBEE', Proceedings of the Sustainable Building Conference (SB05), Tokyo, Japan. pp. 1700- 1705.

Kurek, J., 2007. King Abdullah financial district. Henning larsen architects. 1-7.

Lahn, G., Stevens, P. 2011. '1-36', Burning oil to keep cool: The hidden energy crisis in saudi arabia. Available at:

http://www.chathamhouse.org/sites/default/files/public/Research/Energy,\%20Environ ment\%20and\%20Development/1211pr_lahn_stevens.pdf.

Lee, W., 2013. A comprehensive review of metrics of building environmental assessment schemes. Energy and Buildings. 62, 403-413.

Lee, W., Chau, C., Yik, F., Burnett, J., Tse, M., 2002. On the study of the credit-weighting scale in a building environmental assessment scheme. Building and Environment. 37(12), 1385-1396.

Mao, X., Lu, H., Li, Q. 2009. 'A comparison study of mainstream sustainable/green building rating tools in the world', Management and Service Science, 2009. MASS '09. International Conference on. 20-22 Sept. 2009. IEEEE, pp. 1-5. doi: 10.1109/icmss.2009.5303546.

Rahardjati, R., Khamidi, F., Idrus, A. 2010. 'The Level of Importance of Criteria and Sub Criteria in Green Building Index Malaysia', International Conference on Sustainable Building and Infrastructure (ICSBI 2010). Kuala Lumpur Convention Centre, June 2010. pp. $15-17$

Reed, R., Bilos, A., Wilkinson, S., Schulte, K., 2009. International comparison of sustainable rating tools. JOSRE. 1(1), 1 - 22. 
Reed, R., Wilkinson, S., Bilos, A., Schulte, K. 2011. 'A comparison of international sustainable Building tools- An Update', The 17th Annual Pacific Rim Real Society Conference. Gold Coast, 16-19 January pp. 1- 15.

Reijnders, L., van Roekel, A., 1999. Comprehensiveness and adequacy of tools for the environmental improvement of buildings. Journal of Cleaner Production. 7(3), 221225.

Rosa, L. V., Haddad, A. N., 2013. Assessing the sustainability of existing buildings using the analytic hierarchy process. American Journal of Civil Engineering. Vol 1(1), 24-30.

Saaty, T., 1990. How to make a decision: The Analytic Hierarch Process. European Journal of Operational Research. 48, 9-26.

Saaty, T. L., 2003. Decision-making with the AHP: Why is the principal eigenvector necessary. European Journal of Operational Research. 145(1), 85-91.

Saaty, T. L., 2008. Decision making with the analytic hierarchy process. International Journal of Services Sciences. 1(1), 83-98.

Saaty, T. L., Sodenkamp, M. 2010 'The analytic hierarchy and analytic network measurement processes: The measurement of intangibles', in Zopounidis, C. and Pardalos, P. M. (eds.) Handbook of Multicriteria Analysis. Germany: Springer Berlin Heidelberg, pp. 91-166. 4.

SGBC 2011. Saudi Green Building Council. Available at: http://www.saudigbc.com/.

Shaawat, M. E., Jamil, R., 2014. A guide to environmental building rating system for construction of new buildings in saudi arabia. Emirates Journal for Engineering Research. 19(2), 47-56.

Sinou, M., Kyvelou, S., 2006. Present and future of building performance assessment tools. Management of Environmental Quality: An International Journal. 17 (5), 570 - 586.

Sleeuw, M., 2011a. A comparison of BREEAM and LEED environmental assessment methods. University of East Anglia Estates and Buildings Division, Norwich.

Sleeuw, M. (2011b) A comparison of BREEAM and LEED environmental assessment methods. Norwich. [Online]. Available at: https://www.uea.ac.uk/estates/environmentalpolicy/BREEAM+vs+LEED?mode.

Suzer, O., 2015. A comparative review of environmental concern prioritization: LEED vs other major certification systems. Journal of Environmental Management. 154(0), 266-283.

Terry, A., Moore, T., Casey, M., Andrew, P., Hosking, P., King, T. A., Roussac, C., Raina, D., Hansen, R., McDonald, T., Jackson, S. (2008) 'Waste and sustainable commercial 
buildings'. http://www.yourbuilding.org/Article/NewsDetail.aspx?p=83\&id=1567. Available at: http://www.yourbuilding.org/Article/NewsDetail.aspx?p=83\&id=1567.

Todd, J., Crawley, D., Geissler, S., Lindsey, G., 2001. Comparative assessment of environmental performance tools and the role of the Green Building Challenge. Building Research \& Information. 29(5), 324-335.

Tzeng, G.-H., Huang, J.-J., 2011. Multiple attribute decision making: Methods and applications. Taylor \& Francis Group, Florida.

USGBC (2009) LEED 2009 for New Construction and Major Renovations Rating System With Alternative Compliance Paths For Projects Outside the U.S. Washington, DC

Venkatarama Reddy, B. V., Jagadish, K. S., 2003. Embodied energy of common and alternative building materials and technologies. Energy and Buildings. 35(2), 129137.

Wang, J.-J., Jing, Y.-Y., Zhang, C.-F., Zhao, J.-H., 2009. Review on multi-criteria decision analysis aid in sustainable energy decision-making. Renewable and Sustainable Energy Reviews. 13(9), 2263-2278.

Yang, Y., Li, B., Yao, R., 2010. A method of identifying and weighting indicators of energy efficiency assessment in Chinese residential buildings. Energy Policy. 38(12), 76877697. 